\title{
Las desventuras del puerto de Gijón de 1742 a 1817. \\ Resistir a los hombres y al océano*
}

\author{
The Misfortunes Befalling the Port of Gijon from / 742 to /8/7. \\ Resisting Men and the Ocean
}

\author{
MANUEL-REYES GARCÍA HURTADO \\ Universidad de A Coruña \\ Facultad de Humanidades y Documentación \\ Campus de Esteiro \\ 15403 Ferrol (España) \\ reyes.garcia.hurtado@udc.es

Resumen: El puerto de Gijón, desde la década de los años cuarenta del siglo XVIII, se embarca en un largo y complejo proceso que persigue su reparación, mejora y limpieza. Nos centramos en los 75 años que consideramos cruciales para evidenciar el papel que las distintas jurisdicciones y corporaciones adoptan en este proyecto, explicar las dificultades que unas y otras plantean y los cambios que se experimentan en el modelo de gestión de las obras. Este análisis contribuye a aportar una hipótesis que justifica la debilidad de las infraestructuras portuarias españolas que va más allá de la dificultad que conllevan los trabajos de ingeniería hidráulica o el coste de los mismos, y que radica, en un primer momento, en el hecho de que sean las localidades quienes gestionan las tareas de reconstrucción, en la lucha por el control de los arbitrios que debían financiar las obras y, ya en el siglo XIX, en la aparición de instituciones que cuestionan abiertamente las prácticas anteriores, lo que provoca un enfrentamiento en el que el principal perjudicado será siempre el puerto, aunque saldrá reforzado de este combate final.

Palabras clave: Jurisdicción. Audiencia. Ayuntamiento. Arbitrio. Junta del puerto.

Abstract: As of the 1740s the port of Gijon embarked on a long, complex process aimed at repairing, cleaning and improving its installations. The focus is placed here on the 75 years that, to our mind, were crucial for evincing the role of the different jurisdictions and corporations involved in this project, explaining the difficulties posed by all of them and the changes taking place in the management model of the works. This analysis contributes to put forward a hypothesis justifying the shortcomings of Spanish port infrastructures which went beyond the problems arising from the hydraulic engineering works or their cost. These lay from the start in the fact that it was the localities that managed the reconstruction works, in the struggle over the control of the taxes with which the cost of the works was meant to be defrayed and, in the nineteenth century, in the appearance of institutions that openly questioned the previous practices. All of which led to a conflict of which the port would always be the main victim but nevertheless, from which it would emerge stronger than before.

Keywords: Jurisdiction. Court. Town Council. Taxes. Port board.

\footnotetext{
* Trabajo realizado en el marco del Proyecto I+D de Generación de Conocimiento «Dinámicas y conflictividad en el litoral del Noroeste peninsular en la Edad Moderna» (Referencia: PGC2018-09384I-B-C33), del Ministerio de Ciencia, Innovación y Universidades, con una cofinanciación del $80 \%$ FEDER.
}

MEMORIA Y CIVILIZACIÓN 24 (202I): 423-463 [I-4I] [ISSN: II39-0I07; ISSN-e: 2254-6367] 
Gijón presenta unas características geográficas magníficas a priori, con algunos inconvenientes, para establecer en su rada un puerto que diera servicio tanto a sus habitantes (pesca, comercio) como a la Real Armada (refugio). Ahora bien, todas las infraestructuras marítimas del mar Cantábrico tuvieron que hacer frente de manera permanente a unas condiciones naturales muy difíciles que venían marcadas por la intensidad de los temporales, los vientos, las mareas $y$, hasta muy avanzada la Edad Moderna, la fragilidad de las construcciones, que podían no ser más que un muelle o embarcadero levantado sobre peñascos arrojados por los propios vecinos y que de manera inexorable durante los meses de otoño e invierno sufrían enormes destrozos. Aunque durante la primavera y el verano la climatología permitiera reparar o restaurar esos endebles embarcaderos, para esto hacía falta recursos materiales y contar con el apoyo, si no ya económico al menos político, de las distintas instancias de la administración'. En las siguientes páginas pretendemos mostrar que los obstáculos que debía enfrentar y superar una población para contar con un puerto ${ }^{2}$ iban más allá de los aspectos vinculados exclusivamente con la naturaleza, o los avances en la ingeniería hidráulica ${ }^{3}$, sino que necesitaba derrotar a un tridente que venía dado por las disputas jurisdiccionales, la violenta naturaleza del océano y la intromisión de instancias que eran las que debían haber sido su principal apoyo ${ }^{4}$. La escasez de construcciones que merezcan el calificativo de puertos a finales del Antiguo Régimen en España, y muy concretamente en la cornisa cantábrica ${ }^{5}$, obedece a la suma de unos factores que, sin actuar de manera concertada ni simultánea, condujeron todos a una situación de asfixia, de bloqueo. Esto, más allá de beneficios puntuales a determinados grupos o instituciones, determinó que, a pesar de infinidad de esfuerzos de planeamiento, de imposiciones fiscales, de prolijos informes que las distintas secretarías tuvieron que resolver, los avances, cuando finalice el Antiguo Régimen, estuvieran muy por debajo de los objetivos perseguidos. La responsabilidad es múltiple.

\footnotetext{
I García Hurtado, 2016.

${ }^{2}$ Sobre Gijón es fundamental Adaro Ruiz-Falcó, 1976, I, pp. 65-242; 1986, IV-I, Pp. 73-148, I65-182, 193-240 y 265-279.

${ }^{3}$ García Hurtado, 2020a.

${ }^{4}$ Todo este cúmulo de obstáculos explica, aunque el autor lo hace extensivo al conjunto de Asturias, el título del apartado «El fracaso de las realizaciones de infraestructura portuaria» en Peribáñez Caveda, 1992, pp. 7799.

${ }^{5}$ García Hurtado, 2019, 2020b.
} 


\section{LAS DESVENTURAS DEL PUERTO DE GIJÓN}

\section{I. «DISTURBIOS» EN LA JURISDICCIÓN E INTERESES CREADOS}

El 3 de octubre de 1742 se ordena al comisario de Marina ${ }^{6}$ de Avilés (José Colosía Mier y Noriega) que, en aplicación a la ordenanza de matrículas, averigüe qué fondos son los que se destinan a la reparación de los muelles de Gijón y del resto de Asturias, información que es trasladada por Miguel Jerónimo de Isunza y Quintanadueñas, regente de la Audiencia de Asturias ${ }^{7}$, al secretario de Marina, José del Campillo, el 30 de agosto. Por una real cédula, las facultades relativas al mantenimiento de los puertos habían sido conferidas al infante almirante general de España y las Indias ${ }^{8}$. La literalidad del texto no dejaba lugar a muchas dudas, al menos para la Corona, pero no será así para otras autoridades:

Será también de vuestro encargo que se mantengan los muelles con la firmeza necesaria para la comodidad y seguridad de las personas y mercaderías que se adelanten donde se pueda a recibir las embarcaciones con el fondo suficiente, $y$ que se fortifiquen y adornen a cuenta de los arbitrios que para este género de obras tengo concedido a los puertos de mar; y si mis ministros de Marina recelasen que los caudales que estuvieren aplicados a ellas se malversan y gastan por los consejos y ayuntamientos sin la justificación conveniente y fuera de las destinaciones a que deben servir, les ordenaréis que les pidan cuentas de sus productos y que den la providencia más ajustada para que no continúe este perjuicio`.

Sin embargo, el regente de Asturias se negaba a informar a Colosía, según este denunció ante Campillo el II de mayo de 1742, sobre el destino que las justicias de Lastres, Candás y Gijón daban a los fondos procedentes de los arbitrios cuyo objeto era la construcción, conservación y restauración de los muelles. $\mathrm{Da}$ a entender que se asiste a una vulneración reiterada de la jurisdicción de Marina y que debe ponérsele fin:

y de ello están dichos señores [los ministros de la Audiencia] bien actuados, y no obstante por eso no dejan de proseguir como antes lo hacían; para cuyo remedio, y por no desear yo nueva ocasión de disputa, me veo precisado hacer a vuestra excelencia esta insinuación, suplicándole se sirva ordenarme lo que sea más del servicio de su majestad.

\footnotetext{
${ }^{6}$ Sobre esta figura, Teijeiro de la Rosa, 2012.

${ }^{7}$ Fue regente desde el 28 de octubre de 1739 hasta su muerte en 1749. Menéndez González, 1990, p. 31. Sobre esta institución es fundamental Menéndez González, 2011.

8 Pérez Fernández-Turégano, 2004.

9 Archivo General de Simancas (en adelante, A.G.S.), Secretaría de Marina (en adelante, S.M.), leg. 384. Toda la correspondencia citada en el artículo pertenece a este legajo.
}

MEMORIA Y CIVILIZACIÓN 24 (202I): 423-463 [I-4I] 
Están en juego los puertos, singularmente el de Gijón que amenaza ruina si no se remedia «en lo que queda de verano» ${ }^{10}$. De hecho, le sirve para reiterar su petición a Campillo de que intervenga, a raíz de que unos diputados de Gijón fueron a Avilés, donde residía el comisario, alarmados por el estado de su puerto y «respondí estar esperando la decisión de vuestra excelencia y que hasta tanto yo no podía conocer de nada»". Campillo, el 5 de junio, ordena a Colosía que prosiga sus indagaciones, porque le amparan la real cédula y sus competencias, en todos los puertos donde sospeche que existe algún fraude, no solo en los citados, y al tiempo se le traslada una real orden al regente para que colabore, «sin oposiciones ni disturbios», a fin de que la Marina ejerza su jurisdicción sin intromisiones -el regente debe «exonerarse del conocimiento de los encargos»- - Colosía, con este respaldo expreso, solicita el 5 de julio a los escribanos toda la documentación notarial existente relativa a los muelles y sus obras - provisiones, órdenes, cuentas, etc.-, en suma, los «papeles que conducentes a este asunto se han obrado sin omitir ninguno, todos íntegros y originales». Debían responder en un plazo máximo de tres días bajo apercibimiento de ser multados con 100000 maravedís. Los escribanos, muy lejos de mostrar temor alguno, le indican que solo entregarán lo que les solicita si se lo ordena el regente, a cuya jurisdicción pertenecen. Colosía se ve obligado el 3 de agosto a enviar un oficio al regente donde «de parte de su majestad» le pide que dé curso a su petición ante los escribanos o se verá obligado a «usar de las facultades y recursos que me competen». Al día siguiente el regente comunica que va a enviar a Campillo una relación sobre el asunto y que mientras no llegue su resolución en Asturias esta cuestión queda en suspenso. Esto es una maniobra dilatoria, pues tenía en sus manos la real cédula y la carta de Campillo de 5 de junio que le había hecho llegar el mismo Colosía el 5 de julio, de modo que no había la menor duda de qué pensaba el secretario de Marina y que siempre iba a respaldar a su ministro en el principado, que no hacía sino obedecerle, aunque resulta claro que Colosía tenía un especial interés en avanzar por la vía de los hechos y romper con la inercia de décadas.

La respuesta del regente a esta acción de Colosía será primero contemporizadora ${ }^{12}$ y después contundente. Así, el 8 de agosto, ante un escribano en Oviedo, declara que el ministro de Marina falta a la verdad y que no ha interferido ni obstaculizado para impedir que Colosía conociera el destino y aplicación de los arbitrios concedidos para el mantenimiento de los muelles. Es más, añade que

${ }^{10}$ Colosía a Campillo. Avilés, 28 de agosto de 1742.

11 Colosía a Campillo. Avilés, 22 de septiembre de 1742.

12 El regente traslada a las justicias la orden de colaborar y él ofrece actuar «con rendida obediencia» al secretario de Marina. Isunza a Campillo. Oviedo, 16 de junio de 1742. 


\section{LAS DESVENTURAS DEL PUERTO DE GIJÓN}

jamás ha recibido ningún oficio a este respecto solicitando información alguna. Sí reconoce un hecho que obviamente es el origen del enfrentamiento. Se habían licitado unas obras en el puerto de Gijón, que remataron en el maestro arquitecto José Suárez, para las que el Consejo de Castilla concedió a Gijón, el 20 de febrero, el establecimiento de un arbitrio de dos reales de vellón en cada carga de pescado que se consumiera en el principado y saliera del mismo. La duración del arbitrio se determinaría al finalizar el año, una vez conocido lo que se podía obtener con él y el importe de las obras. Del mismo modo, se le otorgó a Gijón una licencia el 9 de abril para obtener un crédito sobre el arbitrio por el coste de los trabajos en el muelle, con libertad de elección, pero sin que el interés pudiera superar el $3 \circ 4 \%$. Es decir, el propio regente reconoce una actuación que, aunque fuera conocida por el Consejo de Castilla -este no entra en cuestiones jurisdiccionales-, vulneraba abiertamente las competencias del ministro de Marina. Ahora será el ayuntamiento de Gijón el que se encuentre ante una disyuntiva, pues Colosía el 22 de junio lo visita y exige controlar el arbitrio, y la ciudad pregunta al regente qué debe hacer, pues el Consejo de Castilla con quien trató fue con el regente. Este opta, ya había estallado el conflicto, por aconsejar a Gijón que realice la consulta a Campillo. A pesar de todo, el regente subraya que Colosía falsea la realidad, subrayando que existe documentación de cuanto relata y es oficial. Evidentemente, lo que no afirma en ningún momento es que se contara con Colosía para nada de esto ni que se le hiciera partícipe. Es obvio que sí será conocedor, de ahí su denuncia a Campillo, de los manejos del regente y la petición expresa a los escribanos de todos los papeles.

Del conjunto de implicados -escribano mayor de millones y rentas del principado, escribano de cámara y acuerdo de la Audiencia- nadie va a asumir que su comportamiento vulnere las competencias del ministro de Marina y se remiten a que sus actos estaban respaldados por el Consejo de Castilla y los despachos y autos reales. En Lastres la actuación también se hizo al margen del ministro de Marina. Las primeras providencias con el Consejo de Castilla eran de I73I, para reparar una rotura del muelle, que se retoman por otros desperfectos el 2 de junio de 1740, cuando el regente remite un informe de treinta y cuatro páginas. El Consejo actúa sin dar lugar a dudas de que ejerce sus competencias, pues el 6 de septiembre se dirige al regente para averiguar cómo iban las obras, cuánto tiempo faltaba para su finalización, cuál sería el importe, etc. El regente da cumplida respuesta el 5 de noviembre. Todo esto no es sino una muestra de la confusión administrativa y de la ignorancia de qué estaba aconteciendo en los muelles y puertos de España por parte de la Secretaría de Marina. De lo único que no se podía acusar a la Audiencia de Asturias era de actuar de manera secreta. Bien distinto es que hubiera elegido un interlocutor que le dejaba amplia libertad -el Consejo no tenía a nadie sobre el terreno para controlar realmente 
las obras ni los gastos-, y que por tanto la Secretaría de Marina y sus hombres le resultaran una molestia, pues les despojaba del control económico de los arbitrios y de su manejo. Era un hecho que el regente consideraba de su esfera competencial lo relativo a los puertos, lo que no negaba nadie - «en que hasta ahora había entendido la Real Audiencias/ ${ }^{13}$, de modo que es lógico que se sucedieran las disputas con Colosía, porque la Audiencia le impedía ejercitar libremente su jurisdicción de Marina. La tensión generada entre Secretaría de Marina y Audiencia, Secretaría de Marina y Consejo de Castilla, regente y ministro de Marina, en modo alguno debe llevarnos a pensar que se trate de un exceso de celo por contribuir, supervisar, instar a la mejora de las infraestructuras portuarias asturianas; lo que se dirime son parcelas de poder, control de los recursos, la capacidad para primar unas localidades u otras. No hay planificación portuaria ni proyecto alguno que supere el corto plazo, y es fácil colegir que este clima de desconfianza, la falta de colaboración entre las autoridades asturianas y las dependientes de la corte, es un elemento más, muy importante, que entra en juego y que dificulta todavía más llevar a ejecución reparaciones, limpiezas, etc. de las débiles y frágiles infraestructuras portuarias asturianas.

Un problema de jurisdicciones y un problema de personas. Colosía ve en las actuaciones del regente «la voluntariedad con que pretende ponerme de mala fe», le tilda de falaz - «pareciéndome que entre hombres no era menester otra prenda, mediando la palabra»—, considera que le tiene «aversión», que persigue la «provocación» y que se ha llegado a este punto -en julio de 174I ya tuvieron un enfrentamiento, y su antecesor en el cargo padeció lo mismo- porque «en los lances que me ha movido se le trató con bastante benignidad» ${ }^{14}$. Será Campillo el único que adopte una postura fría, pragmática, casi de intermediación, pues es consciente de que, cuestiones legales aparte, el asunto está contaminado por unas relaciones personales irreconciliables - Isunza ha tachado de mentiroso al comisario de Marina; Colosía ha levantado la sospecha de malversación sobre el regente- - Así pues, intenta cerrar la disputa reprendiendo a ambos, a Colosía porque no aprecia ataque a su jurisdicción, a Isunza porque no cree que le esté auxiliando y evitando darle motivos de queja a Colosía. El 3 de octubre escribe Campillo: «que con disputas y competencias no se atrase el servicio». $Y$ dio resultado, pues el 13 de ese mes el regente ordena que todos los documentos relativos a puertos pasen a la Secretaría de Marina.

Pocos meses más tarde, en enero de 1743, cambia la relación de fuerzas y los papeles. Ahora será Colosía el que se muestre díscolo y el regente obediente.

${ }^{13}$ Colosía a Campillo. Avilés, 23 de junio de 1742.
${ }^{14}$ Colosía a Campillo. Avilés, 28 de agosto de 1742. 


\section{LAS DESVENTURAS DEL PUERTO DE GIJÓN}

La reparación del muelle de Gijón se había estimado en 90000 reales, y esta suma debía proceder de los arbitrios. La Real Hacienda determina valerse de la mitad de los arbitrios -entre 8 y 9000 reales al año- para sus fines, ante lo que Colosía protesta el 19 de enero: «quedando por esta razón este muelle sin el reparo de que tanto necesita para no quedar arruinado enteramente en este invierno». En esta ocasión Campillo le da la orden a Isunza y este la asume. Sin embargo, Colosía actúa como lo hizo el regente medio año antes. Colosía, de manera unilateral, suspende la aplicación de la orden y le pregunta a Campillo si debe cumplirla. Se escuda, nuevamente, en el puerto de Gijón:

esperando la [resolución] más favorable a favor de la continuación de aquella obra, que si no se cierran los rompimientos hechos en aquel muelle en el próximo verano, llegará el caso de verle arruinado todo en el invierno, y se ocasionarán los inmensos costos que no ignora vuestra excelencia, y aun la imposibilidad con que se halla toda esta patria por falta de medios con que poder sostener iguales fábricas $^{15}$.

Colosía va a hacer gala de sus competencias jurisdiccionales y se convierte en un activo defensor de la mejora de los puertos asturianos. Su insistencia no fue acompañada del éxito, aunque sus demandas de auxilio eran más que justificadas. Así, cuando el 22 de enero de 1749 un temporal ocasiona notables destrozos en el puerto de Gijón, que en esta ocasión amenazaba con hacer extensivos los daños a la propia villa, en el expediente se lee: «Sin resolución». Lo cierto es que esta respuesta es sorprendente, pues la descripción que ofrece Colosía no deja lugar a dudas de que el deterioro ya estaba próximo a permitir afirmar que Gijón carecía de puerto:

Con la tempestiva fuerza de mar que se experimentó en esta costa el día 22 del corriente, se ocasionaron muchas pérdidas de embarcaciones, casi en todos los puertos de ella, porque habiendo subido las mareas mucho más que lo regular, y aun adonde nunca se han visto, sacó de los puertos y radas dichas embarcaciones, sin que lo embarazasen los muelles, con lo que hallándose la gente en el mejor tiempo para la pesca de besugo, y no siendo posible volver a proveerse de embarcaciones para ella, quedan expuestos a la mayor miseria; y con superior razón la vecindad de la villa de Gijón, que el mismo día tuvo la desgracia de que la furiosa tormenta arruinase casi todo el muelle de tierra y falsease la cabeza del de mar, quedando perdido el puerto y de consiguiente la villa; en la cual, según me avisa aquel ayuntamiento, se anegaron muchas casas, incluso los alfolíes de la sal, y concluye el ayuntamiento en que si no se toma luego alguna providencia para detener las aguas, se dividirá dicha villa en dos mitades, comunicándose el mar de la parte del norte con el que está al mediodía, que si esto sucede se puede dar por perdido

${ }^{15}$ Colosía a Campillo. Avilés, 19 de enero de 1743.

MEMORIA Y CIVILIZACIÓN 24 (202I): 423-463 [I-4I] 
aquel lugar y puerto, siendo como es el más usado de esta provincia y en el que subsiste algún tal cual comercio ${ }^{16}$.

El mismo 22 de enero Juan Bautista Esteban de Salaberri, vicerregente de la Audiencia ${ }^{17}$, había informado a Ensenada desde Oviedo de la tormenta que esa madrugada, entre las cuatro y las cinco, había afectado a Gijón, pues desde el primer momento se apreció que la entrada del puerto había quedado seriamente comprometida al acumularse materiales desprendidos de las cabezas del muelle. Ese mismo día las justicias y regimiento de Gijón remiten una representación a Colosía sobre «la espantosa tormenta de viento y alteración y corriente de mar ${ }^{18}$ y le piden que acuda a la villa para conocer de primera mano el estado del muelle y que solicite a la corte su auxilio. Se había venido abajo lo reformado desde 1742, se había abierto un boquete en el muelle y las cabezas se habían desplomado. Colosía visita la villa el 2 de febrero -la dilación se debió a que estaba efectuando una comisión de montes - y realiza una inspección del puerto acompañado de dos arquitectos ovetenses, «los más prácticos que se conocen en esta provincia» ${ }^{19}$ —Pedro Muñiz Somonte y Pedro Antonio Menéndez-, y de dos regidores gijonenses -Francisco Gregorio de Jovellanos y Gregorio Menéndez Valdés ${ }^{20}$ - El objetivo es conocer las fracturas producidas en el muelle y los peligros a los que se expone la localidad. En su informe los arquitectos afirman:

[el] muelle está por la parte de la mar toda la frente desplomada con muchas aberturas, por las cuales se introduce el viento y golpes de agua, y revientan por infinitas partes... haber derribado la furia del mar como cincuenta pies de sillería en dicha cabeza del muelle por todo su alto, cuyos materiales han caído en la boca de dicho muelle... según la mala disposición en que se halla dicha obra, si no se procura el reparo de su ruina, llegará muy presto el caso de que la acabe de rendir la fuerza del mar, cierre enteramente la boca del puerto, como casi sucede con los materiales que han caído en ella, y consiguiente lleve también el resto del muelle de tierra y haga muchos daños en las casas de esta villa... [el muelle de tierra] se halla toda la frente que mira al mar desunida y apartada del plan y macizo con grandes aberturas e infinitos agujeros, con evidente riesgo de arruinarse por hallarse desexcavados los cimientos y desplomada la obra con muchas panzas, lo que igualmente sucede a la frente de la caja de dicho muelle ${ }^{21}$.

\footnotetext{
${ }^{16}$ Colosía a Ensenada. Avilés, 28 de enero de 1749.

${ }^{17}$ Sobre Salaberri, González de San Segundo, 2014, pp. 777-778.

${ }^{18}$ Ayuntamiento de Gijón a Colosía. Gijón, 22 de enero de 1749.

${ }^{19}$ Colosía a Ensenada. Colunga, 7 de marzo de 1749.

${ }^{20}$ Sobre ambos, Pérez de Castro Pérez, 1998, pp. 246-247.

${ }^{21}$ Firman todos los que participaron en el reconocimiento. Gijón, 4 de febrero de 1749.
} 


\section{LAS DESVENTURAS DEL PUERTO DE GIJÓN}

Se disponía de 20000 reales, generados por los arbitrios para las obras, una cantidad insignificante. Por su parte, el ayuntamiento carecía de recursos para hacer frente a las mismas. Así, todas las rentas de Gijón, arrendadas a Toribio de Sarracina, importaban 49284 reales y 26 maravedís anualmente, que sumados otros ingresos dejaban 61522 reales y 29 maravedís en las arcas. Con esa cifra debía hacer frente a unos gastos fijos de 59577 reales y 5 maravedís. Es decir, la villa disponía para cualquier imprevisto de solo 1945 reales y 24 maravedís ${ }^{22}$. Gijón carecía de fondos, rentas o propios con los que abordar la reparación del muelle. Finalmente, se había demostrado que los citados arbitrios no fueron capaces de lograr una reparación mucho menor en comparación con la que ahora se presentaba. Colosía, en uso de sus competencias como juez conservador de muelles, plantea dos posibilidades, limpiar la entrada del puerto o efectuar una reparación global.

El 12 de marzo, Gregorio Menéndez Valdés, como comisario de la villa de Gijón, remite a Ensenada un plano y un proyecto de reparación que se había encargado al ingeniero Joseph Petit de la Croix (Figura I), de paso en la villa de camino a Ferrol, del que los regidores esperaban que ofreciera el remedio «más adaptable, más seguro, menos costoso y más conveniente ${ }^{23}$. El informe de la Croix ${ }^{24}$, fechado el 15 de febrero, pone de relieve que el puerto, además de los daños estructurales, tenía graves problemas de limpieza - acumulación de arenas y broza-. Propone aprovechar la barra de arena que sale del puerto para construir uno nuevo que permitiría a las embarcaciones dar fondo en él incluso con marea baja - una profundidad de 15 brazas de agua -, mientras que en la época debían hacerlo en plena mar. El presupuesto de la obra ascendería a 293824 reales. La cifra, para la importancia y extensión de los trabajos, no era elevada, pero para Gijón y sus posibilidades era desorbitada. Colosía había enviado el 10 de marzo la misma documentación a Ensenada, y como no recibía respuesta la solicita nuevamente el I 3 de mayo. Las autoridades locales presionan a Colosía, pues el estado del puerto asfixia la maltrecha economía de Gijón, cuyos habitantes se encuentran «en la mayor estrechez por lo que les ha aniquilado las anteriores guerras» ${ }^{25}$. Tienen noticias de que con la paz numerosas embarcaciones se dirigen con géneros a esta villa, pero será imposible que penetren en el puerto y descarguen sus mercancías y puedan cargar otras. Temen que, si no se logra al menos desescombrar su entrada, la noticia de su peligrosidad les llevará a tomar

\footnotetext{
22 Jácome Sánchez Cifuentes, escribano. Gijón, 15 de febrero de 1749.

${ }^{23}$ Francisco Gregorio de Jovellanos y Gregorio Menéndez Valdés a Colosía. Gijón, 15 de febrero de 1749.

${ }^{24}$ Para una enumeración esquemática de los proyectos que se realizaron para el puerto de Gijón, RodríguezVillasante Prieto y Troya Calatayud, 2002, pp. 60-69.

${ }^{25}$ Gregorio Menéndez Valdés a Colosía. Sin fecha (junio de 1749).
}

MEMORIA Y CIVILIZACIÓN 24 (202I): 423-463 [I-4I] 
otro rumbo. Se urge no ya solo a la reparación, sino a que se efectúe una rápida intervención que permita el simple acceso al puerto. Colosía da traslado a Ensenada, con la habitual expresión de que si no se llevan a cabo las reparaciones ese verano el principal puerto del principado quedará completamente inutilizado el siguiente invierno ${ }^{26}$.

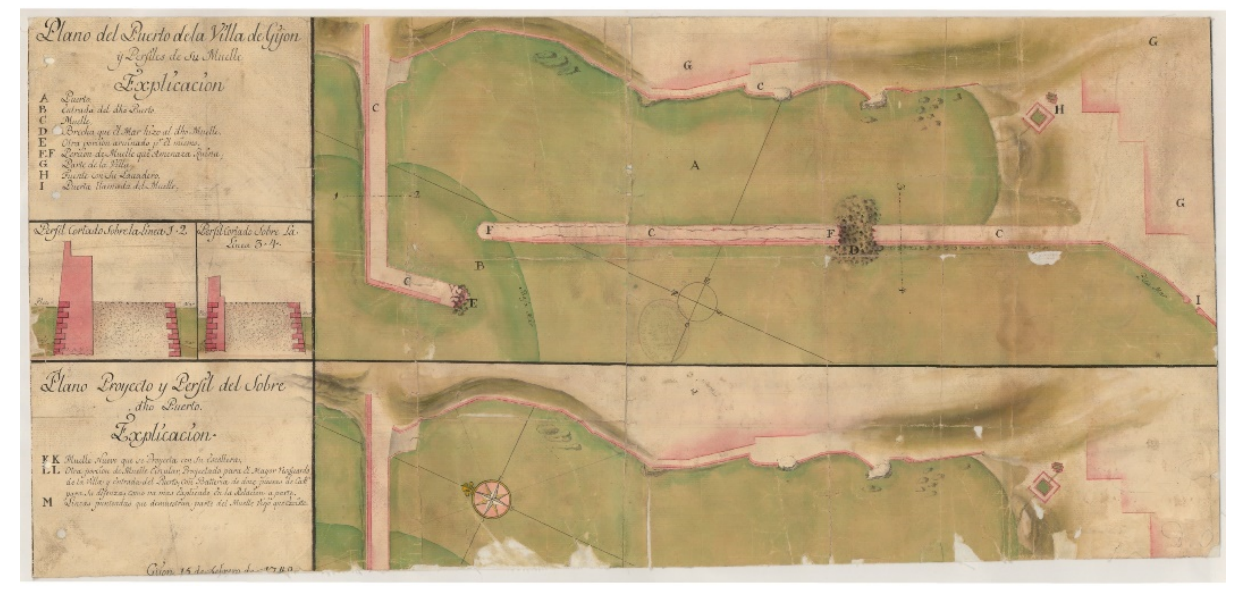

Figura I. Plano del puerto de la villa de Giión y perfiles de su muelle. Giión, 15 de febrero de 1749. 10seph Petit de la Croix (no está firmado) [Cartoteca del Archivo General Militar de Madrid (en adelante, C.A.G.M.M.), O-05/02]

El 20 de marzo de $175 \mathrm{I}$, sin haber obtenido respuesta alguna, la villa otorga un poder al regidor y alférez mayor Francisco Gregorio de Jovellanos para que se desplace a la corte y renueve la petición de auxilio en los mismos términos que dos años antes ${ }^{27}$. Todo pasaba porque se les entregara lo producido por el arbitrio del pescado y por la institución de un nuevo arbitrio. Para lograr financiar la obra, Gijón propone que se establezca desde enero de 1752 un arbitrio de dos reales en fanega de sal consumida en Asturias. El regente, Isidoro Gil de Jaz ${ }^{28}$, se

${ }^{26}$ Colosía a Ensenada. Avilés, 18 de junio de 1749.

27 Sus gastos de manutención en la corte — salió de Oviedo el I de julio de 175 I y regresó el 16 de marzo de 1752- ascendieron a 19150 reales - 1850 reales fueron «en diferentes gastos secretos conducentes a la pretensión» y portes de cartas-, que la villa de Gijón, «no teniendo de qué satisfacerlos», solicita el 2 de diciembre de 1752 al regente que asuma este descubierto. Este requiere autorización a Ensenada para realizar el pago el 3 de enero de 1753 y se le concede el 21 de febrero.

${ }^{28}$ Fue regente de 2 de julio de 1749 a octubre de 1752, y en 1754 hasta el 21 de octubre (Menéndez González señala 1755). En 1752 es nombrado presidente de la Chancillería de Granada, pero no pasará de electo y el 22 de agosto, sin dejar de ser regente según unos y abandonando Asturias según otros, obtiene los honores y sueldo de ministro del Consejo de Castilla. No llegó a desempeñar el cargo en Granada al solicitar la Diputación de Asturias al monarca que lo mantuviera como regente, y regresó a Oviedo. Sus biógrafos 


\section{LAS DESVENTURAS DEL PUERTO DE GIJÓN}

muestra a favor, a pesar de que la sal alcanzaría el precio de 16 reales y medio en fanega, lo que cree que no tendría grandes consecuencias para el consumo ni para la Hacienda:

la gabela que menos sensible se les hace a estos naturales es la que se impone sobre la sal, o porque están acostumbrados a ella o porque manteniéndose los pobres con leche, manteca, castañas y otros comestibles en que no se usa de ella, cesa el clamor de los que con más justicia pudieran quejarse; y por lo que respecta al segundo me parece que, conferida la pérdida que puede haber en cuanto al consumo, con las utilidades que indispensablemente facilitará al real erario dicho puerto, si con la reedificación del muelle se hace accesible a las embarcaciones extranjeras y a las naturales, no merece estimación el perjuicio que se premedita aumentándose algún impuesto a la sal ${ }^{29}$.

En agosto de $175 \mathrm{I}$ los directores generales de rentas solicitan al regente que detalle quién recibe los cinco reales y medio del arbitrio en fanega de sal, qué documentos acreditan su derecho y a qué se destinan ${ }^{30}$. Los beneficiarios eran el principado - un real, desde 1726 y prorrogado cada nueve años, para sus gastos ordinarios, y tres reales con otros fines-, la Universidad -medio real, para dote y aumento de cátedras - y la catedral de Oviedo (un real). El principado, por una provisión de 18 de abril de 174I, empleaba los ingresos en los intereses de dos censos a favor del marqués de Tolosa y del duque del Parque, en mantener el regimiento de milicias, en sufragar los gastos de un pleito por las rentas provinciales ante el Consejo de Hacienda y, por provisión de 23 de junio de 1740, para abonar el premio (talla) a quienes matasen lobos y otras fieras. A finales de diciembre de $175 \mathrm{I}$ acumulaba 536319 reales y medio, cantidad que el 17 de diciembre de 1749 había solicitado destinar a la construcción de una carretera que comunicara Asturias con León, que estaba a la espera de aprobación por el Consejo de Castilla. La catedral recibía este arbitrio por una provisión de 29 de octubre de 1726 y una real cédula de I de noviembre del mismo año, que le fue concedido para realizar obras de reparación en su torre, destruida por un rayo el 13 de diciembre de 1723. La última prórroga había finalizado el 5 de marzo de 1748, pero el cabildo percibió el arbitrio en 1749 y solicitaba el de 1750, sobre la base de que por un decreto de 22 de diciembre de 1740 la Corona había estado recibiendo hasta 1749 la mitad y en aquel documento se concedía

difieren en las fechas y cargos efectivos. Maruri Orrantia, 200I, pp. 92-94; Juanto Jiménez, 20I2, pp. 120$12 \mathrm{I}$. Se le reconoce como la persona de mayor prestigio que pasó por la Audiencia en el siglo XVIII y como promotor de caminos y puertos. Menéndez González, 1990, p. 32. El muelle de Gijón podía cuestionar esta apreciación.

${ }^{29}$ Isidoro Gil de Jaz a Ensenada. Oviedo, 15 de septiembre de 175 I.

${ }^{30}$ Luis de Ibarra y Larrea y Francisco de Cuéllar a Gil de Jaz. Madrid, 4 de agosto de I75I.

MEMORIA Y CIVILIZACIÓN 24 (202I): 423-463 [I-4I] 
una prórroga para poder resarcirse de la reducción. El debate se suscita porque en el decreto se habla de «ciudades, villas y pueblos», no de cabildos, además de no haber sido contribuyente. Si solo debía recibir lo correspondiente hasta 1748 eran 42 II 0 reales, si se le creía comprendido en quienes eran citados en el decreto la suma sería superior. Sin embargo, y esto no lo negará el cabildo, reparada la torre, el arbitrio se había empleado en «adornos interiores de la iglesia, como fábrica de órganos, dorar retablos y otros gastos de esta naturaleza» ${ }^{31}$. Es decir, ateniéndose a la finalidad inicial del arbitrio concedido, se había incumplido la misma. Esta idea determina al regente a suspender la entrega del arbitrio al cabildo en 1750 y a realizar una consulta al Consejo de Castilla el 17 de marzo, aunque él no tiene dudas sobre cuál debe ser la resolución:

Esta limosna involuntaria a que se precisa a los vasallos, no solamente sin su consentimiento, si no es con su repugnancia, la oigo censurar, mayormente empleándose en obras para que por derecho canónico están destinadas las primicias y subsidiariamente los diezmos (...) limosna gravosa y repugnante a los mismos que la hacen, minora el consumo del efecto de la sal en perjuicio de la regalía [ I I reales en fanega] ${ }^{32}$.

El cabildo había comisionado a la corte a un canónigo para lograr que se le entregara la cantidad retenida y que se prorrogara el arbitrio. Debe defenderse de la grave acusación del regente y lo hace declarando ser cierto que han empleado el arbitrio en la construcción de dos órganos y adornos, pero que este era el objeto de la concesión en 1738 y la prórroga de I743. Es más, adopta una actitud acusatoria. Afirma que el regente en 1749 no puso reparo alguno y que cambió de parecer al año siguiente. No solo le acusa de retener su dinero, sino que le responsabiliza de que al no haber expresado repulsa en 1749, el cabildo, seguro de estos ingresos, había solicitado un crédito de 132066 reales «para perfeccionar las obras». Si dejaban de percibir el arbitrio que les había permitido afrontar gastos obligados, ahora el mismo se iba a convertir en la causa de un endeudamiento al que no podían hacer frente ${ }^{33}$.

Los directores de rentas asumen en su totalidad el informe del regente $y$ requieren de Ensenada que les notifique cómo deben actuar ${ }^{34}$. La decisión final de la dirección general de rentas será que el principado redima el censo del marqués de Tolosa, de modo que se dispondrá de 12000 reales más anualmente, y que los tres reales que antes expusimos que tenían diversos fines se destinaran

${ }^{31}$ Gil de Jaz a Bartolomé de Valencia y Luis de Ibarra y Larrea. Oviedo, 18 de agosto de 175 I.

32 Gil de Jaz a Bartolomé de Valencia y Luis de Ibarra y Larrea. Oviedo, 18 de agosto de I75I.

33 El cabildo de Oviedo a Ensenada. Oviedo, 22 de diciembre de 1751.

34 Bartolomé de Valencia y Luis de Ibarra y Larrea a Ensenada. Madrid, 27 de noviembre de I75I. 


\section{LAS DESVENTURAS DEL PUERTO DE GIJÓN}

en su totalidad al puerto de Gijón, que debe primar sobre la carretera, ya que de nada serviría esta sin aquel. Se mantiene el real de la Iglesia, pero ahora destinado al puerto ${ }^{35}$ y, cuando este se concluyera, a la carretera. Eliminado el censo, quedarían del arbitrio II6 319 reales en I75I, a los que se debían sumar los 42000 retenidos en 1750 y la misma cantidad de $175 \mathrm{I}$, reclamados por el cabildo ovetense, y 50000 del arbitrio del pescado. Por tanto, Gijón tendría a su disposición para empezar las obras 250319 reales. A esto se sumaría, desde el 27 de septiembre de 1752, el importe destinado al vestuario del regimiento de milicias de Oviedo, que se suspende durante cinco años y se ordena al regente que se emplee en el puerto y la carretera, y otro real más sobre los cinco y medio ${ }^{36}$.

El I de septiembre de 175 I el regente acusó recibo a Ensenada de la recepción de la representación de Colosía, del plano y presupuesto de la Croix y de un memorial de Jovellanos y se compromete a informar en breve por «la gravedad del asunto ${ }^{37}$. Se muestra partidario de cuanto se solicita e incluso vincula el puerto de Gijón a la proyectada carretera - «la carretera es como preparación para el muelle de Gijón, y el muelle complemento de la carretera ${ }^{38}$ y sugiere -aún no se ha resuelto al respecto- que el real del cabildo pase al puerto - resulta evidente que lo que no deseaba era que la catedral recibiera ni un maravedí más-, de modo que en ocho años, o en cuatro si se aumenta otro real, se recaudaría lo preciso para abonar el coste de las obras de Gijón. El regente, «sin que haga ejemplar para sus sucesores», recibe el 27 de septiembre de 1752 las facultades de intendente de provincia, de modo que se convierte en el responsable de la administración del arbitrio de la sal y de la dirección de las obras, tanto del muelle como de la carretera. Este papel ha de entenderse como ejecutivo, pues desde el punto de vista práctico, él mismo se lo había reconocido a Ensenada, carecía de formación para dictaminar en cuestiones técnicas, aspecto para el que se contará con un ingeniero. El elegido el 7 de noviembre de 1752 por el comandante general del Departamento de Ferrol, Cosme Álvarez, será el ingeniero extraordinario Thomas O'Daly ${ }^{39}$, encargado de reconocer los posibles puertos montañosos para abrir la carretera -había participado en las obras de Guadarrama - y del muelle de Gijón. Todo estaba en movimiento, pues también desde Ferrol se había enviado un piloto de la Armada, Francisco Leal, para que

\footnotetext{
35 El cabildo de Oviedo responde con una representación impresa dirigida al rey donde expone sus argumentos, denuncia el ataque de algunos émulos y expone la importancia de las obras en un templo, ya que «todas las utilidades públicas dependen de considerar, como principal objeto, las espirituales y divinas».

${ }^{36}$ Oficio al obispo gobernador del Consejo. Buen Retiro, 27 de septiembre de 1752.

${ }^{37}$ Gil de Jaz a Ensenada. Oviedo, I de septiembre de I75I. Respuesta a la carta de Ensenada de 25 de agosto.

${ }^{38}$ Gil de Jaz a Ensenada. Oviedo, 15 de septiembre de 1751.

${ }^{39}$ Su hoja de servicios en A.G.S., Secretaría de Guerra, leg. 3793, carp. 2, fol. 45.
}

MEMORIA Y CIVILIZACIÓN 24 (202I): 423-463 [I-4I] 
sondeara el puerto y levantara un plano - la Croix estaba enfermo y Cosme Álvarez no quiere enviar a sus ingenieros principales, mientras que «los otros son todavía muy tiernos» ${ }^{40}$ - hasta el cabo de Torres ${ }^{41}$. El cantero Marcos de Vierna, quien va a realizar el proyecto de la carretera, también reconoció el muelle de Gijón. Las cifras que se manejan para la carretera dejan en una nimiedad lo que se debía destinar a Gijón, pues el tramo de León a Oviedo se evaluaba en 4500000 reales, y de esta ciudad a Gijón en I 300000 reales $^{42}$.

El cabildo de Oviedo, durante años defensor del arbitrio de la sal, presenta un memorial el 29 de febrero de 1752 solicitando que no se le apliquen los dos reales concedidos para la apertura de la carretera a León y la reparación del muelle de Gijón. Nuevamente el regente - a quien Ensenada solicita el 28 de febrero de 1753 que informe- y el cabildo vuelven a encontrarse.

Pese a todas las declaraciones a favor, el muelle de Gijón continuaba en junio de 1753 en el mismo estado - más exacto sería decir peor, por el tiempo transcurrido y su exposición al océano-, por lo que a instancias del ayuntamiento y de O'Daly el regente solicita a Ensenada poder disponer del arbitrio sobre el pescado - en esa fecha ya acumulaba 80000 reales- e iniciar las obras y limpiar la dársena y la entrada ${ }^{43}$. El ayuntamiento expone su desazón por contar con resoluciones de la Corona para disponer de recursos, con el nombramiento del regente para dirigir las obras y que, sin embargo, la situación sea de parálisis en el terreno de los hechos:

El continuado clamor con que asusta este vecindario anunciando la próxima ruina que amaga a una gran parte del lugar el desbarato del muelle que, sobre el estado infeliz en que vuestra señoría le ha visto, tuvo posteriormente ruinas tan considerables que vencidas las murallas que cubren el lugar, con cualquier alteración bate el mar libremente los cimientos de las casas con evidente riesgo de inundarlas ${ }^{44}$.

Gijón tiene mucho cuidado de no resultar ofensivo — «lejos de recelar el ayuntamiento parecer molesto en esta instancia»- $y$ añade que si el regente no

${ }^{40}$ Cosme Álvarez a Ensenada. Ferrol, 10 de octubre de 1752. A.G.S., S.M., leg. 384.

${ }^{41}$ Gil de Jaz a Ensenada. Oviedo, 8 de noviembre de 1752. Este piloto desarrolla la idea de un puerto nuevo en la punta de Piedra Lladra - la idea era de la Croix, al comprobar que la dársena de Gijón apenas tenía 50 varas de ancho por 300 de largo-, que garantizaba la profundidad de 20 pies en bajamar que exige un navío, pues por su emplazamiento nunca podría recibir más que pataches y de manera excepcional embarcaciones de 100 toneladas. La composición del muelle la calcula en 39I 765 reales y el nuevo puerto en 5807440 reales. Cosme Álvarez a Ensenada. Ferrol, 28 de noviembre y 26 de diciembre de 1752.

42 Las obras desde Oviedo a la cordillera cantábrica no comenzarán hasta junio de 177I, con un presupuesto anual de 540000 reales, y de Oviedo a Gijón en 1782, siendo comisionado Jovellanos para supervisar este tramo. Alvargonzález Rodríguez, 2012, p. 21 I.

43 Gil de Jaz a Ensenada. Oviedo, 20 de junio de 1753.

${ }^{44}$ El ayuntamiento de Gijón a Gil de Jaz. Gijón, 16 de junio de 1753. 


\section{LAS DESVENTURAS DEL PUERTO DE GIJÓN}

puede ordenar el inicio de las obras que informe a la corte, que es lo que hizo. Como una suerte de círculo vicioso, el 18 de julio de 1753 Ensenada ordena a Cosme Álvarez que vuelva a enviar a Gijón al ingeniero O'Daly, pasando antes por Oviedo para acordar con el regente «el mejor modo y brevedad de reparar el muelle de Gijón», que el rey ha mandado que se ejecute. Esa misma fecha se notifica a Gil de Jaz que disponga de los fondos de los arbitrios de pescado y sal, de manera que las obras se inicien aprovechando la estación veraniega, quien el 25 escribe a Ensenada afirmando que en cuanto llegue O'Daly a Gijón comenzarán las obras.

Así pues, en el verano de 1753 el maltrecho muelle de Gijón iba a recibir la atención que durante años solo se le había dispensado de palabra y por escrito, pero jamás de facto. No obstante, desde el primer momento se evidencia que el proceso no será fácil. A juicio del regente, el proyecto de O'Daly no se restringe a una simple reparación, «el precepto que se me había dirigido», sino que cambia la disposición del muelle, además de tener un presupuesto de 648469 reales, «cuyo dinero no existe», por lo que determina remitir el plano y el proyecto a Ensenada y que él disponga ${ }^{45}$. En otro lugar llega a escribir «que para este reparo bastaba un maestro de obras conocido suyo ${ }^{46}$. En cualquier caso, por lo avanzado del verano no se pueden comenzar los trabajos, y la actividad se limita a extraer y labrar piedra y aprovisionarse de los materiales precisos para cuando llegue la primavera.

Pasados los años, se evidencia que los resultados no serán acordes con lo esperado. Un oficio de Antonio Varela Vermúdez, regente a la sazón ${ }^{47}$, al secretario de Marina, Julián de Arriaga, arrojará luz sobre lo acontecido, pues en la corte «ha hecho mucha novedad» ${ }^{48}$ la noticia de que faltaban fondos para continuar los trabajos en el puerto, algo imposible sobre la base de que disponía de una asignación específica. Arriaga exige el 3 I de octubre una explicación detallada de los caudales dispuestos y de su destino. La sorpresa del secretario de Marina tenía muchos motivos. Él mismo, tras sustituir a Ensenada, firmó la orden de 2 de octubre de 1754 por la que se decretó que se efectuara solo la reparación del muelle - este era el parecer de Jorge Juan ${ }^{49}$-, posteriormente la de 4 de diciembre para que se llevara a cabo la obra conforme a la idea de O'Daly plasmada en

45 Gil de Jaz a Ensenada. Oviedo, 19 de septiembre de 1753.

${ }^{46}$ Debe referirse sin duda al maestro arquitecto Pedro Menéndez, que fue el encargado de la construcción del Hospicio ovetense y que reconoció el muelle de Gijón junto a O'Daly.

47 Desempeñó el cargo desde agosto de 1755 a 21 de noviembre de 1763, fecha de su fallecimiento. Menéndez González, 1990, p. 33.

48 Oficio a Antonio Varela Vermúdez. Madrid, 3I de octubre de I76I.

${ }^{49}$ Estudia los planos enviados por Cosme Álvarez y Gil de Jaz. En su decisión cita a Gil de Jaz y su afirmación de que el rey solo ha solicitado una reparación, mientras que O'Daly propone un nuevo muelle de tierra, 
su plano de 1753 (Figura 2), ya que los muelles estaban minados en sus cimientos y exigían una actuación más amplia, y la de 16 de diciembre por la que se despojaba de toda autoridad sobre el ingeniero al regente y se reducía su papel a aportar los caudales procedentes de los impuestos que financiaban los trabajos. Tras la caída en desgracia de Ensenada es O'Daly el que reactiva el tema del muelle. En una carta que dirige a Arriaga, al tiempo que le felicita por su designación y se coloca a sus órdenes, afirma que ha aprovechado el tiempo transcurrido desde su nombramiento el I 8 de julio de 1753 en mejorar su proyecto inicial (Figura 3), el que el regente envió a Ensenada criticándolo, aprovechando que la obra «está retardada ya un año». Lo que él persigue es un puerto de mayor capacidad y que también proteja a la villa ${ }^{50}$. O'Daly triunfa sobre el criterio de la Audiencia, y la marcha de Gil de Jaz a la corte con una plaza en el Consejo, el 2 de octubre de 1754 - curiosamente el mismo día que desde Madrid se envía la orden de activar las obras-, suscita que O'Daly pregunte a Arriaga el 16 de octubre a quién debe acudir en lo concerniente al muelle, ial regidor interino ${ }^{51} \mathrm{o}$ al comisario de Marina de Asturias ${ }^{52}$ ? La desaparición de escena de Gil de Jaz, que había ostentado todo el poder en materia portuaria, abre un debate-conflicto que solo se resolverá a nivel global cuando la Secretaría de Marina asuma la dirección de todas las obras marítimas del reino en $1786^{53}$. Pero para eso faltaban más de treinta años, por lo que es lógico que el II de noviembre se le responda a O'Daly que se dirija a Salaberri «para las providencias de caudal». En cualquier caso, se aprecia que la Audiencia solo tiene el cometido de poner a disposición los recursos, nada más. Era un primer paso en la dirección que culmina en 1786.

colocar más afuera el antiguo, reparar el muelle de mar y hacer una cabeza del dique nueva y más externa. Jorge Juan a Ensenada. Madrid, 19 de julio de 1754. Al día siguiente Ensenada es arrestado y destituido, lo que supone otro paréntesis de inacción hasta que Arriaga adopte una decisión sobre Gijón en octubre.

50 O’Daly a Arriaga. Gijón, 28 de agosto de 1754.

51 Francisco José Fernández de Madrid ocupó la regencia interina entre el primero y el segundo mandato de Gil de Jaz, de 1752 a 1754. Menéndez González, 1990, p. 33.

52 Salaberri a Arriaga. Gijón, 16 de octubre de 1754.

53 Los ingenieros de Marina asumen la dirección de las obras portuarias por el real decreto de 8 de febrero de I78I y la real cédula de 26 de enero de 1786: «Ni el Consejo [de Hacienda], ni ayuntamiento, ni otra persona ha de intervenir ni mezclarse en la dirección de las obras, ni en cosa relativa a ellas; pues solo el oficial o arquitecto encargado correrá con todo, dando cuenta a la Junta del Departamento», artículo IV del Real Decreto de $|78|$. 


\section{LAS DESVENTURAS DEL PUERTO DE GIJÓN}

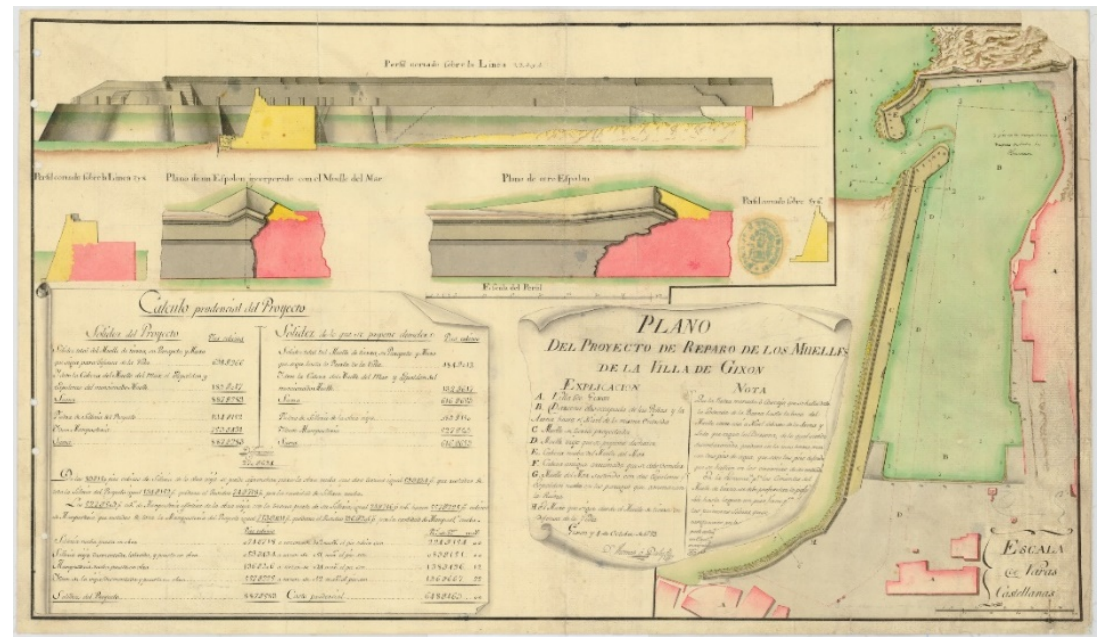

Figura 2. Plano del Proyecto de Reparo de los Muelles de la Villa de Gijón D. Tomás ó Dalep, Gijón, 4 de octubre de 1753 (C.A.G.M.M., O-05/05)

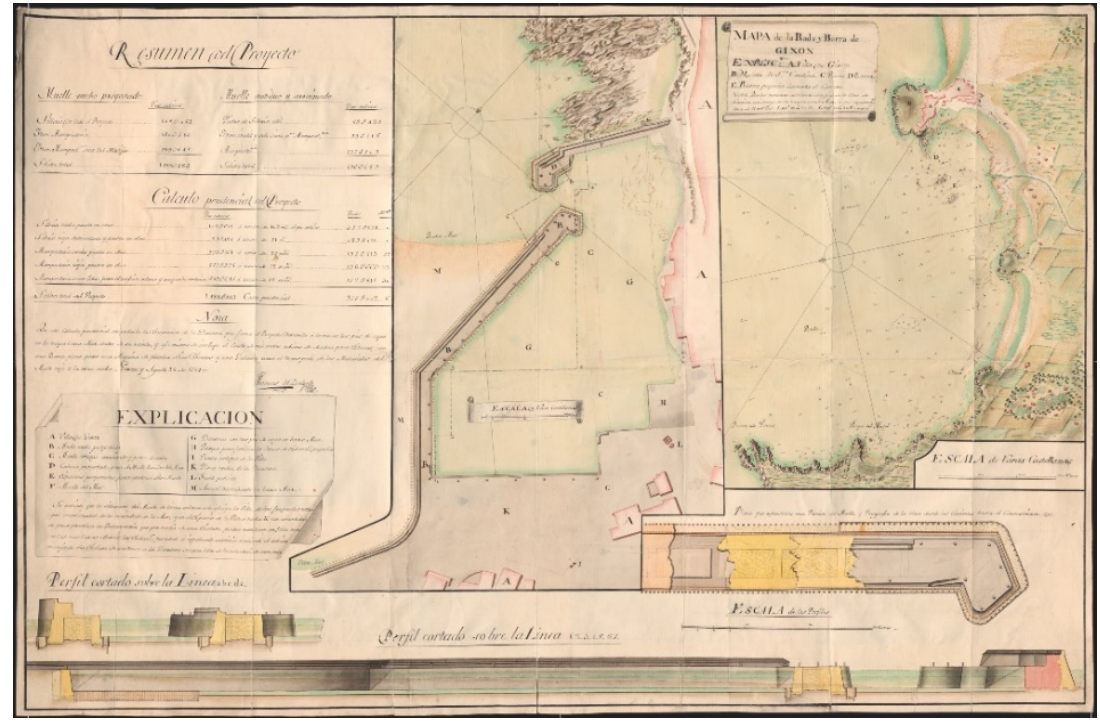

Figura 3. Mapa de la Rada y Barra de Gijón [rúbrica] Tomás O’Daly, Gijón, 28 de agosto de 1754 (Archivo del Museo Naval de Madrid, E-35-18)

En modo alguno el camino de O'Daly quedaba expedito desde entonces, pues ahora será otra instancia, la de aduanas, la que le plantea numerosos problemas, llegando incluso a intentar su detención. Resulta evidente que el exceso de celo o la total ausencia de colaboración reinaban en el puerto de Gijón entre los servidores del rey: 


\section{MANUEL-REYES GARCÍA HURTADO}

Señor, habiendo el día 12 del corriente mes de noviembre ocurrido a las funciones de mi obligación al muelle de esta villa de Gijón, como ingeniero encargado en virtud de real orden a su reedificación, me hallé precisado, con el motivo de un fuerte aguacero, de buscar el abrigo de uno de los navíos ingleses, que a la sazón se hallaron más cercanos y arrimados al muelle, sin que guarda alguno de los muchos que asistieron me diesen ni la más leve insinuación para desistir. $Y$ habiendo salido de a bordo luego que pasó el agua, me hallé citado por el administrador de las reales aduanas de esta villa, don Antonio Rocandío, acompañado de un escribano, de entregarme para ser registrado, y siendo que me presenté públicamente, con mi uniforme, sin bulto ni rebozo, resistí negándome con los debidos términos a un ultraje tan público, como pueden deponer infinitos testigos que se hallaron presentes, sin atender con semejante conducta, y la de llegar a detenerme con la ropa al preciso decoro que en esta, como en las demás particulares, se observa con los oficiales que tienen la honra de servir en los ejércitos de su majestad.

(...) lo que igualmente hago [informar] al señor conde de Valparaíso [Juan Francisco de Gaona y Portocarrero, secretario de Hacienda], suplicándole de mandar a dicho administrador de las reales aduanas de esta villa satisfacer a su inaudita conducta conmigo, y además el no causarme el impedimento diario de acudir dentro de este muelle a todos los sitios y puestos que necesitan mi presencia y ejercicio de mi empleo ${ }^{54}$.

Y Salaberri no adopta una actitud más colaboradora, desde la primera toma de contacto entre ambos. Cuando O'Daly le solicita una gabarra para trabajos en la escollera, el regente interino le indica que se ha informado y que para esa tarea le sirve una lancha de pesca. De nada sirve que le explique que una lancha con 40 quintales cala dos pies de agua, mientras que una gabarra puede cargar más de 400. Manifiesta cierta desesperación e incredulidad:

lo participo a vuestra señoría, cuyas órdenes aguardo en este particular como en los demás semejantes, que enteramente inutilizan mi asistencia en este destino, contradiciendo las reales órdenes, y mezclándose en las disposiciones que solo pertenecen al ingeniero director ${ }^{55}$.

Arriaga muestra enorme diligencia en la solución de los problemas que se le plantean desde Gijón, y con Salaberri y O'Daly adopta una actitud con la que en ocasiones satisface a uno y en otras a otro. Pero había funcionarios de la Corona que no estaban bajo su control, y aquí reaparece lo que la documentación califica de «poca armonía», «mala fe» y de «encuentros y recursos» entre O’Daly

\footnotetext{
54 O’Daly a Arriaga. Gijón, 13 de noviembre de 1754. Arriaga se compromete a hablar del asunto con el conde de Valparaíso.

55 O’Daly a Arriaga. Gijón, 27 de noviembre de 1754. El 16 de diciembre Arriaga escribe a Salaberri y a O’Daly, avisando al primero de que no embarace las providencias del segundo.
} 


\section{LAS DESVENTURAS DEL PUERTO DE GIJÓN}

y el administrador de rentas de Gijón. La situación es tal que Arriaga solicita a Salaberri que ponga paz entre ellos. En esta ocasión (abril de 1755) el motivo será que el administrador desea cobrar derechos sobre las jarcias y otros pertrechos que han llegado para la construcción de la gabarra, a lo que se niega el ingeniero pues su destino es una embarcación que trabajará en las obras del puerto.

Desde el 26 de septiembre de 1759 — fecha del último informe que envía a Arriaga, donde solicita que se suspendan las obras durante el invierno y se trabaje en labrar piedra y prevenir materiales, que aprueba Arriaga el 3 de octubre- O'Daly disfrutará de una licencia y su próximo destino será Puerto Rico ${ }^{56}$. Abandona Gijón sin notificar que no regresará — solo le unía a esa población el muelle-, y lo que era un permiso para ir a la corte por cuatro meses, transcurrido mucho más de ese tiempo, el regente manifiesta que «tengo entendido se ha dignado la piedad de su majestad darle nuevo empleo» ${ }^{57}$. Antes de salir de España ${ }^{58}$, el 9 de agosto de 1760, se le requiere por la Corona que informe del estado del muelle, de la cuenta y razón, materiales, operarios, etc. Casi coincidiendo con la salida de O'Daly, en marzo de 1760, deja también el proyecto el contador y superintendente de la obra desde noviembre de 1753, Fernando Coronel —en realidad, se hallaba ausente desde junio de 1757-, quien había sido nombrado por Gil de Jaz, eligiéndose a la persona que recomienda Varela Vermúdez - «que nombre al que le parezca» ${ }^{9}$-, Pedro Lanza Trelles. Por tanto, quienes llevan la contabilidad serán siempre personas de la máxima confianza de los regentes. En el ínterin, el regente vuelve a ejercer todo el poder, pues su hombre de confianza, Menéndez, desempeña las tareas de ingeniero y contador —esto último desde junio de 1757-, aunque sabe que esta decisión no es operativa:

me ha hecho ver la experiencia que muchos sujetos de aquel puerto se interesan en ella [la obra] por medio de sus familiares y criados, enviándolos a trabajar algunas horas que los excusan en sus casas, sin que lo pueda enmendar el maestro por no ser de su inspección este cuidado ${ }^{60}$.

${ }^{56}$ En la isla, además de continuar con su tarea militar mejorando las defensas — su carrera prosigue alcanzando el grado de coronel-, se convertirá en propietario de una hacienda azucarera (Hacienda San Patricio) y jugará un importante papel en el establecimiento de otros irlandeses. García Leduc, 2007, p. 172; Hinarejos Martín, 2015.

57 Varela Vermúdez a Arriaga. Oviedo, 28 de mayo de 1760.

${ }^{58}$ En I 76 I se le otorga la licencia para viajar a Puerto Rico. Archivo General de Indias, Sección de Contratación, sig. 5505, N. I, R. 32.

59 Aprobado el 29 de octubre de 1760. El regente insiste en diversas ocasiones y para hacer más atractiva su propuesta ofrece rebajarle el sueldo de 500 a 300 ducados, destinando la diferencia a la obra.

60 Varela Vermúdez a Arriaga. Oviedo, 17 de octubre de 1760.

MEMORIA Y CIVILIZACIÓN 24 (202I): 423-463 [I-4I] 


\section{MANUEL-REYES GARCÍA HURTADO}

Bien sabía el regente a qué se refería cuando hablaba de que en la obra había individuos vinculados familiarmente o sus criados. Cuando fallece Francisco Lanza Trelles, tesorero de las obras (hermano del contador), diversas personas le solicitan el puesto, a lo que él les responde que deben acudir a Arriaga. Al mismo tiempo él escribe al secretario de Marina:

Yo me hallo precisado a mirar y a atender a un criado que me ha servido algunos años que se llama don Benito Coello, sujeto de conducta muy acreditada, como es público en toda esta provincia y de que tengo larga experiencia.

Suplico a vuestra excelencia tenga a bien elegirle con el salario de su antecesor, que dará todas las fianzas necesarias, $y$ a que quedaré con el mayor reconocimiento ${ }^{61}$.

El oficial de la Secretaría de Marina que leyó el anterior documento anotó:

Esta fábrica del muelle es un pegote en la Secretaría de Marina: los caudales son arbitrios, cuya inspección no nos compete; la obra dirigida por ingenieros. Fórmese un extracto desde su origen para dar cuenta al rey.

Arriaga desea deshacerse del expediente del muelle de Gijón, en línea con el contenido de la anterior cita e informa a Esquilache en 1766:

Y notando yo en la secuela de semanaria correspondencia con el regente de Asturias reducirse solo a avisarme lo que en la misma obra se distribuye ${ }^{62}$, he reflexionado que siendo esta costeada por arbitrios que paga el común, y que se practica por ingenieros, sin que en Marina se entienda, ni reconozca, ni intervenga en ella, resulta propiamente de la aparente dependencia de mi Ministerio el que sobre ella se descuide, cuando nada sabe.

Por estas razones he manifestado al rey estar este expediente impropiamente en esta Secretaría de mi cargo, y lo paso a vuestra excelencia a fin de que pueda tomar en él el conocimiento que le parezca preciso ${ }^{63}$.

En línea con esto, en 1768 la Audiencia saca las obras por asiento y se adjudican en mayo a Pedro Antonio Menéndez, al que ya conocemos, por 508580 reales, comprometiéndose a finalizarlas en cuatro años. Esta decisión se

${ }^{61}$ Manuel de Verdeja, regente desde diciembre de 1763 hasta su muerte el 30 de abril de 1766, a Arriaga. Oviedo, 17 de abril de 1765. Frente a su protegido opta la persona que venía sustituyendo a Francisco Lanza (Manuel Martínez Valdés), que propone ceder la mitad de su sueldo a la viuda e hijos de Lanza, y que tenía una experiencia de trece años en las obras.

${ }^{62}$ Es cierto que el regente se limita a cursar los gastos semanales, pero también el secretario de Marina -al menos mientras la obra la dirigió O'Daly - recibía informes sobre el avance de los trabajos. O'Daly a Arriaga. Gijón, 26 de mayo de 1756. Le da a conocer que ha finalizado el interior de la dársena de 473 pies de largo y 6 de grueso y el estado del resto.

${ }^{63}$ Arriaga a Esquilache. Palacio, 22 de julio de 1765. 


\section{LAS DESVENTURAS DEL PUERTO DE GIJÓN}

justifica por calcularse en dos millones de reales los ya invertidos en el muelle, por los salarios a que había que hacer frente con el sistema de administración (contador, tesorero, etc.) y porque cesó el arbitrio de tres reales en fanega de sal ${ }^{64}$. Quizá por demasiado voluntarismo o por incapacidad, transcurrido el plazo, el muelle no está rematado y el maestro arquitecto, la villa y la Audiencia dirimen sus diferencias en la sala segunda de gobierno del Consejo. El expediente se resistía a abandonar la corte. En este contexto el Consejo, en un auto de 17 de junio de 1772, ordena que el teniente de navío Diego Guiral, cuya embarcación se encontraba fondeada en Gijón, efectuara una serie de reconocimientos en las obras $^{65}$, lo que lleva a cabo el 14 de julio. Por un oficio del ayuntamiento tenemos una completa descripción del estado del puerto, donde hay motivos de esperanza, pero no se ocultan los problemas. Se subraya la necesidad de una «limpia radical de la dársena» y se alerta de que una parte del muelle de mar "está aventado, respirando agua y viento por la superficie, y levantándose el macizo del paredón del resguardo del lugar» ${ }^{66}$.

Lo cierto es que en Gijón aconteció algo usual y que veremos más tarde que se denuncia abiertamente a principios del XIX. Los presupuestos que se elaboraron para el muelle - esto es válido para cualquier otra infraestructura $\circ$ edificación- estaban muy por debajo de lo que resultaría el coste final. Para explicar esto no hay que pensar en malversación o negligencia - que tampoco se puede descartar siempre-, sino simplemente tener presente que cualquier labor de ingeniería o de arquitectura durante su proceso de realización debe hacer frente a numerosos imprevistos que surgen sobre la marcha y que nunca se contemplan a priori - por desconocimiento o improvisación-. Al presentar las cifras lo que se pretende es la aceptación en la corte, y lo mismo acontece con los arbitrios. Cuando se propone aplicar un arbitrio sobre un producto es norma que el solicitante añada que será solo necesario durante un periodo determinado de tiempo y que con él se cubrirán todos los gastos. Finalmente, pasados unos años se solicita incrementar el arbitrio o incluso innovar con otros, y ni así se alcanza nunca a abonar el total del importe de la obra. Recordemos que el proyecto de la Croix era de 293824 reales en 1749, pues el «costo prudencial» del de O'Daly ascendía en 1754 a 977002 reales y 6 maravedís, es decir, más del triple en un plazo de cinco años. En noviembre de $176 \mid$ se habían depositado sobre las aguas del puerto de Gijón I 304354 reales y 6 maravedís, mientras que

\footnotetext{
64 Antonio de Veyán y Monteagudo, regente de 1766 a 1770, a Arriaga. Oviedo, 9 de julio de 1768.

65 Pedro Rodríguez de Campomanes a Arriaga. Madrid, 22 de junio de 1772.

66 Los regidores de Gijón. Gijón, 10 de febrero de 1772. Archivo General de Marina «Álvaro de Bazán» (en adelante, A.G.M.A.B.), Puertos, leg. 5639/23.
} 


\section{MANUEL-REYES GARCÍA HURTADO}

todos los fondos aportados eran 900582 reales y 24 maravedís -era lo producido por todos los arbitrios destinados a las obras del muelle y de la carretera-, lo que evidenciaba un exceso de gasto de 403 77I reales y 16 maravedís. Las obras tardaron en iniciarse, pero una vez comenzadas se evitó su paralización haciendo uso de los recursos destinados a otros puertos (Lastres) y al vestuario del regimiento de milicias, con el compromiso de reembolsar todo el dinero cuando se le pidiese. $Y$ esto sucede en I76I, y si a las autoridades de Lastres podía hacérseles caso omiso, no sucedía lo mismo con el inspector de milicias. Según el regente, se impone en Gijón reducir el número de trabajadores para hacer economías, pero se descarta abandonar el proyecto:

Bien considero señor excelentísimo no está la obra en estado de dejarse, aunque parece falta aún casi la mitad de ella, porque no se pierda tanto caudal gastado. Pero también es cierto que el ingeniero proyectó y delineó a toda su satisfacción, sin atención a los arbitrios destinados, ni se le pudo hacer ver la imposibilidad de su conclusión en muchos años y a tanta costa, ni representar a vuestra excelencia los justos motivos que pudiera haber para ceñirla o reducirla, acaso con igual seguridad y beneficio, por no haberse visto el plano que formó dicho ingeniero y el avance que pudo haber hecho a toda la obra, la que por lo mismo es forzoso camine desde ahora con lentitud, como hasta aquí lo fue con más calor de lo que permitían sus fondos $y$ arbitrios ${ }^{67}$.

En la corte las justificaciones del regente no encuentran eco y son desmontadas. Las obras del muelle de Gijón no eran más que una excusa para ocultar el incumplimiento sistemático por parte de la Audiencia de las órdenes recibidas:

A lo primero es preciso entender que en el decreto que cita del año de 1752 no solamente se concede los dos arbitrios que nomina, sino también que se aplique todo el sobrante de arbitrios a la obra, y nada de esto se hizo, como que inútilmente se gastaron más de 200000 reales en calzadas que hoy es preciso consumir más de otro tanto para reparar el perjuicio que causaron por la mala disposición.

No habla el señor regente de que pasa de 300000 reales los que tienen prestados los arbitrios del principado al hospicio ${ }^{68}$ y debe recobrar y aprontar para la obra del muelle, como que así es la orden de 1752 que cita...

\footnotetext{
${ }^{67}$ Varela Vermúdez a Arriaga. Oviedo, II de noviembre de I76I. A.G.S., S.M., leg. 384.

68 «Según noticias particulares y verbales, parece que el regente tenía más interés en la obra de caminos que en la del muelle, y que del dinero destinado a este separó alguna partida para el hospicio que estableció en Oviedo»s. Sin fecha. Presentó el proyecto al rey el I de septiembre de I75I y se inauguró el I de enero de 1752. El Hospicio pasa por ser «una de las actuaciones más notables e importantes de la Real Audiencia de Asturias y de su regente». Juanto Jiménez, 2012, p. 127; Junceda Avello, 1984. Su proyecto detalla la financiación, que obviamente no se ajustó a la realidad. Mallada Álvarez, 2015, pp. 2086-2087. Los biógrafos de Gil de Jaz ensalzan el Hospicio como «la obra de su vida», culminación de su «incesante actividad reformista». Coronas González, 2007, pp. 197, 203-208 y 212-215.
} 


\section{LAS DESVENTURAS DEL PUERTO DE GIJÓN}

En el tercer párrafo incluye lo producido y gastado, pero nada dice de lo prestado y consumido en fines diversos.

(...) En el segundo párrafo es un bachiller que tampoco tiene más grado, y los siguientes al cuarto se ve que quiere salir apoyado lo del segundo, y si no se hubiera hecho con el plan que se aprobó aquí por su majestad nunca sería obra perfecta ni valdría nada.

Todo esto tiene remedio con renovar con fuerza lo mandado, que busquen lo prestado y consumido en calzadas, y lo principal, que el principado no tenga intervención, como se mandó, conocido los caciques que ocultan y callan lo prevenido y así lo enredan, $y$ es preciso mano fuerte.

El regente había responsabilizado al ingeniero, que había solicitado un destino en América cansado de las autoridades locales y de la Audiencia, de la elevada suma y de la dilatación en el tiempo. Es curiosa su afirmación, pues una tercera parte de la superficie del plano de O'Daly lo ocupa un detallado presupuesto, que era imposible no haber visto si se aprobó su proyecto, como así fue de hecho, por lo que estaba acusando, como acabamos de ver, a la Secretaría de Marina, aunque no lo hiciera conscientemente. Lo que resulta indudable es la quiebra económica y que desde 1749 a I76I el muelle seguía siendo un problema para Gijón. Sin embargo, la villa de Gijón poco podía lograr, pues su débil muelle va a ser solo un instrumento para disputas entre jurisdicciones en Asturias, ninguna de las cuales va a demostrar más que interés por acrecentar sus rentas y debilitar el poder de sus adversarias. El principal enemigo del muelle nunca fue el mar Cantábrico.

Con el apoyo primero de Ensenada y ahora de Arriaga, las obras se iniciaron y prosiguieron. No se detienen, pero avanzarán muy despacio. Por la cartografía podemos seguir el desarrollo de las mismas. El 22 de febrero de 1765, a solicitud del regente, el marqués de Esquilache informa a Arriaga de la orden que ha expedido para que el ingeniero director Francisco Llobet pase a Gijón e informe del estado de las obras del muelle, «con toda individualidad, claridad y distinción, especificando el estado en que se halla, su firmeza y seguridad, el gasto y costo que podrá tener hasta su total conclusión, y dentro de qué tiempo se podrá evacuar». El motivo de este informe radicaba en que «según los inteligentes» el muelle había resultado «defectuoso» ${ }^{69}$. En 1765, los planos del ingeniero Francisco Llobet (Figuras 4 y 5) y el de Maximiliano de la Croix (Figura 6) señalan todo lo que resta por construir. Llamamos la atención sobre la propuesta para modificar la cabeza del muelle de tierra y evitar que los barcos ofrezcan su costado al entrar en el puerto, el reforzamiento con una muralla de la parte externa

${ }^{69}$ El marqués de Casa Tremañes (capitán general de Galicia) al marqués González de Castejón (secretario de Marina). Madrid, 14 de junio de 1776. 
del muelle de mar para cubrir la obra antigua y darle resistencia, la construcción de una muralla para cerrar la dársena, que posteriormente se derribará - señalada con una «V» en las figuras 5 y 6 -, cómo con la excepción de la entrada del puerto toda la dársena queda en seco en bajamar y la insistencia en excavar el fondo de peña viva - «Y» en las figuras 5 y 6 - hasta el nivel de bajamar, que perdurará en el tiempo, cuando no reviste dificultad técnica al encontrarse en un espacio que las aguas cubren solo unas horas al día. Más allá de la construcción, se evidencia la necesidad de una limpieza de arenas intensa y constante.
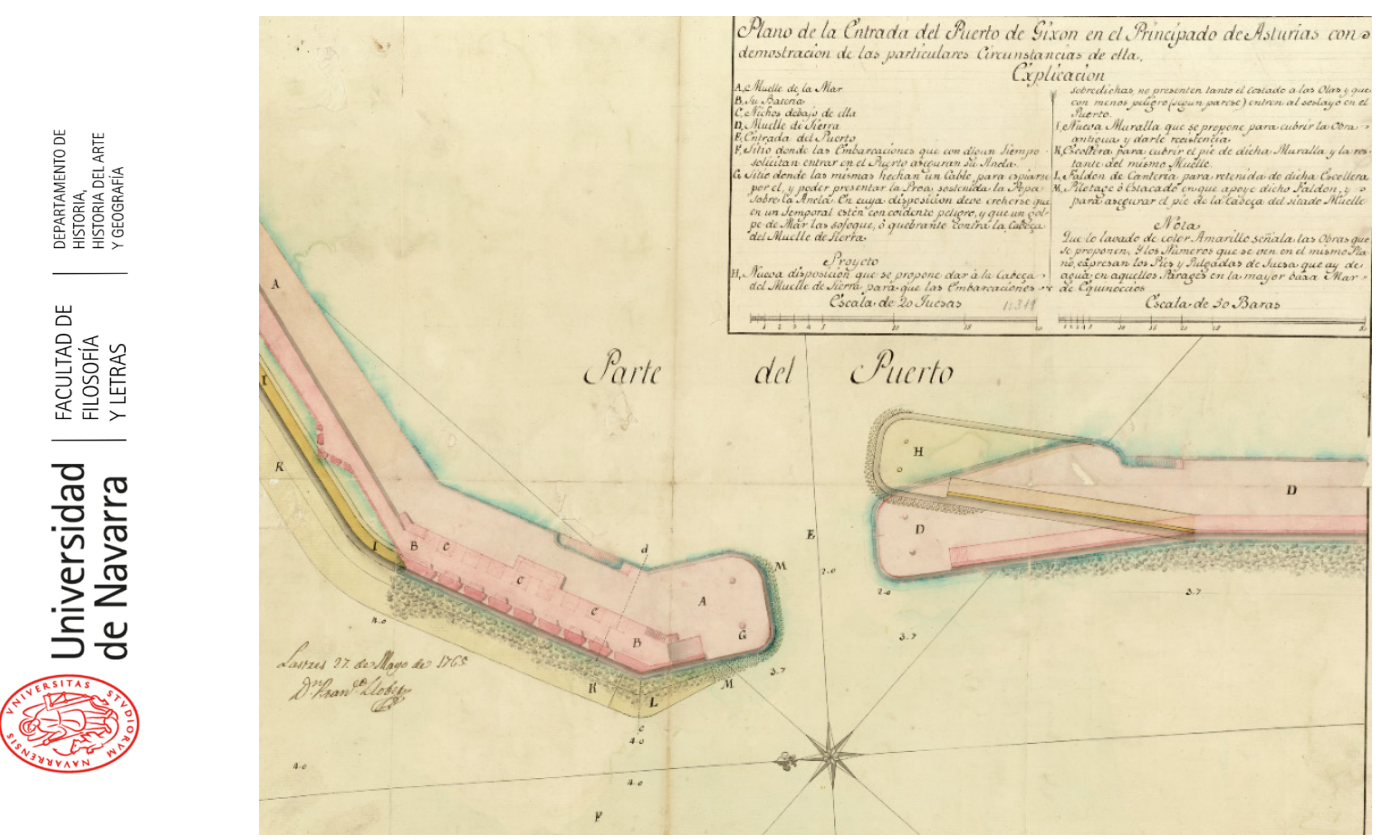

Figura 4. Plano de la Entrada del puerto de Giión en el principado de Asturias con demostración de las particulares circunstancias de ella. Lastres 27 de Mayo de 1765. D. Francisco Llobet [Cartoteca del Centro Geográfico del Ejército (en adelante, C.C.G.E.), Ar.E-T.5-C.I-2I] 


\section{LAS DESVENTURAS DEL PUERTO DE GIJÓN}

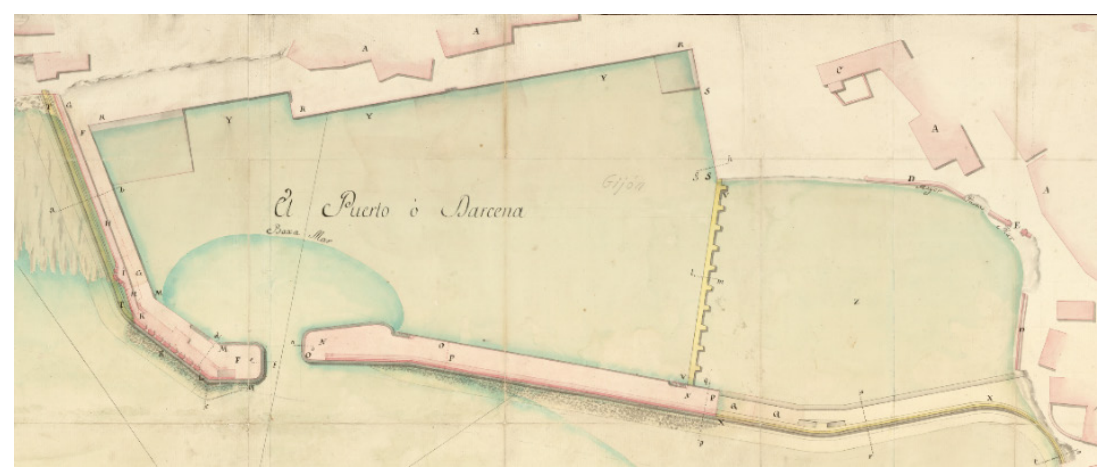

Figura 5. Detalle del plano del puerto de Gijón en la costa y principado de Asturias, con demostración de el estado presente de las obras ejecutadas en él, consistencia de las mismas y de las que parece faltan para la entera conclusión de dicho puerto. Lastres 27 de mayo de I 765. D. Francisco Llobet [C.C.G.E., Ar.E-T.5-C.I-20(a)]

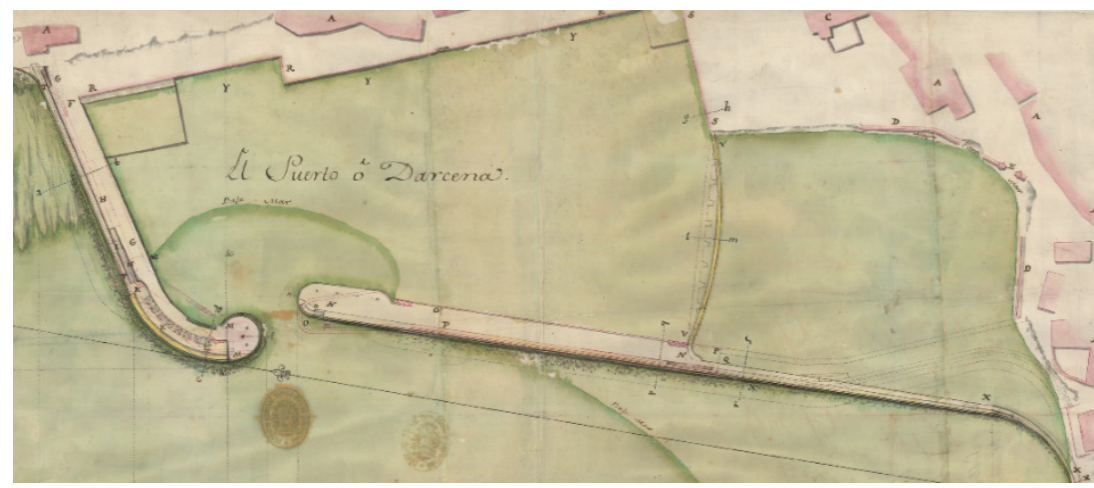

Figura 6. Detalle del plano del puerto de Gijón en la costa del principado de Asturias, manifestando su estado actual por los puntos de Carmin; el de su proyecto con puntos negros y el de este posterior dictamen respectante a las reparaciones e inovaciones que en el mismo se proponen para su mayor solidez y facilidad de su entrada según se distingue por las líneas negras dadas de amarillo. D. Maximiliano de la Croix, Madrid, 7 de octubre de 1765 (C.A.G.M.M., O-05-0I)

En 1776 se quiso dar un impulso al muelle empleando el informe de Llobet, pero había desaparecido. Tres años más tarde (Figura 7) se está llevando a cabo el desescombro de peñas de la dársena (5), se está demoliendo la traviesa de la dársena que era muy peligrosa durante el flujo y reflujo (6), se iba a prolongar 350 pies un paredón (7) para proteger el barrio del Matadero, se está construyendo un muro para terraplenar un gran agujero empleando lo extraído de la dársena (10), se proyecta un paredón en la calle Canto de la Riba para evitar el deslizamiento del terreno sobre la dársena (II), se plantea un muro para cerrar la dársena una vez eliminada la traviesa (I2) y se decide levantar un paredón en 
la zona de San Lorenzo porque el mar penetra y está llevándose la tierra (I5). Como vemos, las tareas se extienden ahora al entorno del puerto.

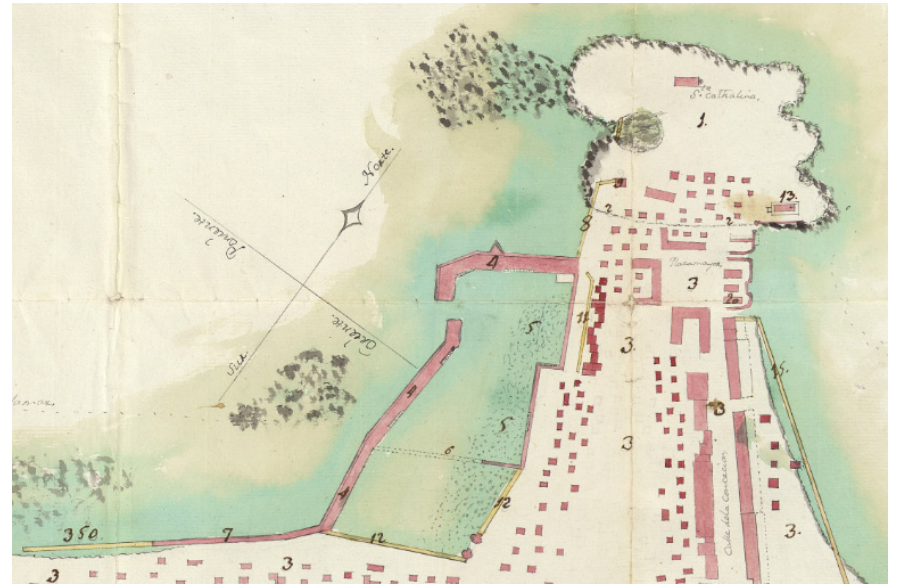

Figura 7. Detalle del Plano del puerto de Gijón, I779. Arquitecto Manuel Reguera González (Archivo Histórico Nacional, Consejos, Mapas, Planos y Dibujos 1886)

En los años 70 y 80 el puerto va a tener un gran abogado en la corte y en el principado: Jovellanos. Cuando el 30 de agosto de 1782 presenta su plan de mejoras para Gijón - que fue aprobado totalmente por el ayuntamiento- el puerto se halla presente. Así, afirma que hay que lograr la seguridad del puerto y proteger la zona oriental de la villa del azote de las arenas. «El primer objeto se ha conseguido casi enteramente con la construcción del nuevo muelle y limpia de su dársena, en que se está trabajando; y en el segundo se ha logrado una considerable ventaja con el paredón de San Lorenzo que acaba de construirse» ${ }^{70}$. Incluso diseña la inscripción que debe colocarse en la dársena, como era obligado en toda obra pública: «Regnante Ferdinando VI optimo principe / provincia asturiensis oere propio. / Demolito vetere, novum portum extruxit. / Faeliciter imperante Carolo III P. P. ampliavit / perfectumque reddidit. / Anno MDCCLXXXIII» ${ }^{71}$. Considera que el puerto es clave para el desarrollo de Gijón, porque es preciso atraer a personas acaudaladas que fijen allí su residencia, y el hecho de que fuera habilitado por el reglamento de 16 de octubre de 1765, con

\footnotetext{
${ }^{70}$ Jovellanos, Plan general de mejoras, p. 2.

${ }^{71}$ Jovellanos, Plan general de mejoras, p. 6.
} 


\section{LAS DESVENTURAS DEL PUERTO DE GIJÓN}

otros ocho puertos peninsulares, para el libre comercio con América era su mejor baza ${ }^{72}$. $Y$ es esta nueva condición de Gijón la que sirve a Jovellanos para responsabilizar al «silencio» e «indiferencia» de Oviedo, a su falta de apoyo, que Gijón no haya obtenido en 1778 un consulado de comercio, que tiene su raíz en la oposición sistemática a cualquier petición para mejorar la villa, ya fuera el puerto o la carretera con Castilla. Según Jovellanos, el pretexto del que hacen gala la capital del principado y todos sus émulos «fue derramar una voz casi común, que encarecía los defectos de su puerto, hasta el punto de hacerle casi inútilı ${ }^{73}$. Para desmontar esta idea expone las bondades de la rada y describe el estado actual del puerto, donde se muestra excesivamente triunfalista:

La nueva dársena, cuya capacidad se ha triplicado respecto de la antigua, ganando además de cuatro a cinco pies de fondo, puede contener con seguridad doscientos buques de trescientas toneladas, $y$ tiene todas las comodidades precisas para el uso de la pesca, carga y descarga de efectos, carena, construcción y demás usos y exigencias del comercio marítimo.

Dos grandes defectos achacan a esta dársena los émulos de Gijón, a saber, que los buques quedan en seco en bajamar, y que en marea sufren y trabajan por la inquietud de las aguas. Pero el primero de estos defectos, sobre ser común a muchos buenos puertos, es de corta consideración; cotejado con las ventajas de ser su fondo muy limpio, de hacer la carga y descarga sobre la misma población; y el segundo, que solo tiene lugar en tiempo borrascoso, se va desvaneciendo a proporción que se aumenta y se desembaraza el fondo de la dársena, cuya limpia, ya muy adelantada, le dará hasta siete pies de más agua que la antigua, y resultará por consiguiente más tranquilo el movimiento de su superficie ${ }^{74}$.

Para aprovechar la oportunidad del libre comercio de modo relevante Asturias hubiera precisado de una producción excedentaria inexistente, de una red caminera interior, entonces ínfima, y de un puerto de Gijón en mejores condiciones. A esto habría que añadir que no se consiguiera un consulado de comercio, debido «a la escasa presión que ejercieron los comerciantes gijonenses y asturianos, o a la poca entidad de los mismos, así como al nulo apoyo que las autoridades del principado de Asturias dieron a esta petición de la villa de Gijón» ${ }^{75}$. En cualquier caso, es indudable que las obras avanzan. Oficialmente, en enero de 1789

\footnotetext{
72 Sobre el papel de los puertos como catalizadores del comercio, de las vías de comunicación y de la configuración urbana y social, Pozas Pozas, 2015; Franch Benavent, 2020.

73 Jovellanos, «Exposición al ministro», pp. 513 y 514.

74 Jovellanos, «Exposición al ministro», p. 5|4. Llega a afirmar que si se ha producido algún accidente se ha debido a la impericia de los pilotos o a «su codiciosa resistencia a tomar práctico». Es incuestionable que el acceso a la dársena era peligroso.

75 Peribáñez Caveda, 1988, p. 48.
} 
la Corona considera que el puerto está ya casi finalizado, lo que justifica que apruebe que los ingresos procedentes de la sal que financian las obras, así como cualquier otro arbitrio del que fuera beneficiario, se destinen al proyecto de puerto de Ribadesella elaborado por el ingeniero de Marina Miguel de la Puente, hasta su conclusión. En ese momento los recursos se dedicarían a otro puerto. Las obras «de corta entidad» que faltan en Gijón deben financiarse con el fondo que disponga, con los derechos de avería y barricaje y con la sidra en la villa y su concejo. Si precisa más dinero, se señala que lo solicite al Consejo de Castilla ${ }^{76}$. $\mathrm{Ni}$ las obras estaban concluidas ni la financiación era tan sencilla. Por otro lado, recurrente, la administración ignoraba que cualquier construcción necesitaba un mantenimiento, y cuando se trataba de ingeniería hidráulica era todavía más ineludible, y puede que igual de costoso que la propia obra, pues era una inversión que debía ser permanente. Con este apartado no se contaba jamás en los presupuestos.

\section{UN ENEMIGO CERCANO Y SORPRESIVO}

En la segunda década del siglo XIX tiene lugar una serie de hechos muy relevantes para el puerto de Gijón con el surgimiento de una nueva institución encargada de dirigir los trabajos de construcción y limpieza. Esta tendrá que superar enormes resistencias para poder desarrollar sus competencias, porque conforme avanza en su implantación van a conocerse decisiones previas que tuvieron consecuencias negativas sobre el muelle y que las autoridades locales intentarán primero ocultar y después justificar. En el contexto del final del Antiguo Régimen afloran las resistencias de quienes han detentado el poder sin ningún control. El muelle tuvo que combatir, como hemos visto, intereses de la Iglesia ovetense o de la Audiencia, y ahora también, lo que podía parecer inexplicable en un primer momento, del ayuntamiento de la villa, que no va a plantear obviamente su lucha como un ataque al puerto, pero cuyas actuaciones van a ser tan lesivas para el mismo como las de sus viejos contendientes del siglo XVIII.

\footnotetext{
76 Pedro López de Lerena, secretario de Hacienda, al superintendente general de la Real Hacienda. Palacio, 29 de enero de 1789. A.G.M.A.B., Puertos, leg. 5639/23. 


\section{LAS DESVENTURAS DEL PUERTO DE GIJÓN}

Finalizada la Guerra de Independencia, en 1815 el comandante de Marina de Gijón ${ }^{77}$ da cuenta al Almirantazgo ${ }^{78}$ del mal estado del puerto y reclama los fondos destinados a su mejora, haciendo uso de sus competencias ${ }^{79}$, a lo que se opone el ayuntamiento. Se inicia así un prolijo y extenso expediente que nos posibilita averiguar y comprender los motivos de que no haya correlación entre las medidas adoptadas desde Madrid y los resultados experimentados en el puerto de Gijón desde las últimas décadas del XVIII a esta fecha. Todo se inicia el 15 de enero de 1772. Ese día el Consejo de Castilla ordenó al regente que, teniendo en cuenta la opinión del ayuntamiento y de dos representantes del comercio, indicase qué derechos - y sobre qué productos- se podrían cobrar con los que financiar las obras de conservación del puerto. Esto se vio sancionado por la real cédula de 27 de enero de 1774. El I5 de febrero de 1804 el comandante de Marina traslada a la Secretaría de Marina una representación de los comerciantes en la que se denuncia el mal estado de la dársena, donde el fondo disminuía de manera constante, sugiriendo que se aplique el producto del derecho de avería, que abonaba por el reglamento de 12 de octubre de 1778, «o al menos el remanente que quedase después de pagados 12500 reales en que estaba pensionado este fondo para la Escuela de Dibujo de Oviedo», creada en 1802. Así se aprobó por una real orden el 31 de marzo de 1804. No debemos pasar por alto que el ingreso de la avería estaba financiando una escuela en Oviedo, de modo que el importe no solo no se invertía en Gijón, sino que nada llegaba al puerto. Lo exiguo del remanente de avería lleva al comandante a señalar que la solución es sencilla y se reduce a que el ayuntamiento dé cumplimiento a lo ordenado en 1774 , a lo que había hecho caso omiso durante exactamente treinta años. El ayuntamiento no va a aceptar en modo alguno y se abre un largo proceso de petición de informes de unos y otros que no concluye hasta el 8 de julio de 1807. El triunfo recae sobre el puerto, pero la guerra impide que tenga efecto en la práctica:

se previno por el anterior Almirantazgo se invirtiesen también precisamente en la limpieza y conservación del puerto, no solo el remanente del derecho de avería,

\footnotetext{
77 El capitán de fragata José Corvera y Falla. Los comandantes de Marina de Gijón en este periodo son: de I80 I a 1803 el capitán de fragata Pablo Pérez; de 1804 a 1808 el capitán de navío Hermenegildo Barrera; no disponemos de datos de 1809 y 1810 ; en $18 \mathrm{I} \mathrm{I}$ el empleo está en blanco en el Estado General de la Armada y en 1812 solo figura «interino», pero sin ningún nombre en todos los empleos de la provincia; de 1813 a 1820 el capitán de fragata José Corvera y Falla, capitán de navío graduado desde 1816 y desde 1818 de la Real y Militar Orden de San Hermenegildo.

${ }^{78}$ El Consejo del Almirantazgo tenía las funciones de asesor del almirante y de tribunal supremo del fuero de Marina. Vázquez Cienfuegos, 2012.

79 «A la jurisdicción militar de Marina corresponden... todo lo relativo a la seguridad y limpieza de los puertos». Ordenanza de S.M., I802, tít. VI, art. III, p. 120.
} 


\section{MANUEL-REYES GARCÍA HURTADO}

ya destinado, sino así mismo los 12500 reales asignados a la escuela de Oviedo y que el comandante de Marina indagase en qué estado se hallaba la obra del Puerto de Vega, a la cual se habían consignado 3000 reales $^{80}$ del propio fondo ${ }^{81}$; pero habiendo sobrevenido al año siguiente la invasión de los enemigos, se emplearon entonces todos los caudales en el preferible objeto de la guerra y por consiguiente sin que nada se adelantase en la limpieza de la dársena.

Finalizada la contienda bélica en Asturias, el comandante de Marina renueva sus instancias y desde la Secretaría de Marina el I 3 de septiembre de I8I2 se solicita información del estado del puerto (Figura 8) y de los fondos al ayuntamiento, a los diputados del comercio y al comandante. Los dos últimos alertan de que el puerto se va a cegar, que solo con mareas altas pueden entrar las embarcaciones, y en 1813 las que excedieran de 160 toneladas ya no podrían acceder. La respuesta del ayuntamiento no abrigaba ninguna esperanza para el puerto:

El ayuntamiento, acompañando copia de la citada cédula del Consejo de 1774 , manifestaba que por el mismo Consejo se había determinado se pagase un cirujano, de que carecía aquella villa, dándole 400 ducados al año del fondo de propios y arbitrios que se recaudaba por el ayuntamiento; que lo que sobraba, después de pagadas sus obligaciones más necesarias, se aplicaba a las obras públicas que más lo exigían, ya en la dársena y fuentes como en el empedrado de las calles.

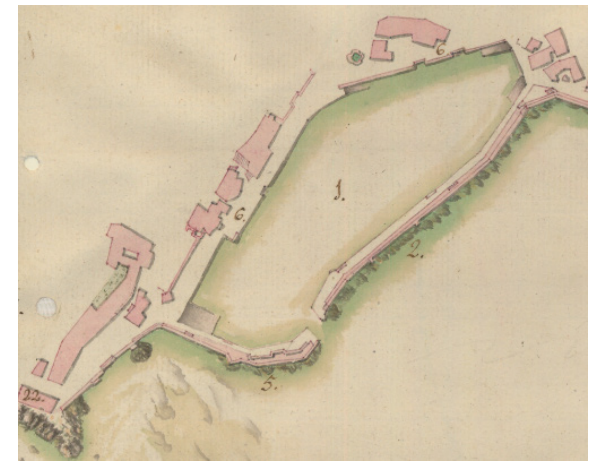

Figura 8. Detalle de plano del puerto y villa de Gijón en Asturias. Ramón Lope, año de I8/2 (C.A.G.M.M., O-05/03)

${ }^{80}$ La batería, concluida a fines de I800, se financiaba con el derecho de avería de Gijón. Félix Ignacio de Tejada, capitán general del Departamento de Ferrol, a Francisco Gil y Lemos, director general de la Armada. Ferrol, I de agosto de 1807. Los 3000 reales no se pueden dejar de abonar, porque los recibe el comerciante ovetense Méndez Vigo desde el 16 de diciembre de 1802, para devolverle los 21970 reales que adelantó para la batería. José de Espinosa, secretario del Almirantazgo y jefe de escuadra, al inspector general de Marina. Madrid, 13 de agosto de 1807.

${ }^{81}$ Representación de la Junta a Manuel Godoy. Gijón, 25 de abril de 1807. 


\section{LAS DESVENTURAS DEL PUERTO DE GIJÓN}

Ante posturas tan encontradas, el 5 de marzo de 1815 se ordena que los diferentes actores gijonenses expresaran su parecer sobre la administración de los arbitrios. El comandante de Marina expone el día 22 que el ayuntamiento consideraba suyo el arbitrio sobre el barricaje, de modo que le entregaba lo que consideraba oportuno. Así pues, en tres años el puerto había recibido solo 6000 reales, cuando los ingresos por este concepto superaban los 36000 reales. Del arbitrio de avería recibía lo que ya señalamos, hasta que el II de marzo de 1813 el ayuntamiento decidió abonar con él los salarios de los maestros y empleados en el Instituto Asturiano - con el compromiso de reintegrar el importe total, que jamás cumplió-. Propone que se aplique la real cédula de 1774 y que recaiga la recaudación en los comerciantes, bajo su dirección. Por su parte, el ayuntamiento, el 25 de marzo, se jacta de que actúa conforme a sus facultades, que sus cuentas han sido aprobadas por el Consejo Real y añade que siempre ha atendido a la limpieza de la dársena, citando los mencionados 6000 reales que invirtió en 1813. Se niega a acceder a la petición del diputado del comercio de que aporte las cuentas del fondo procedente del arbitrio de avería debido a que «los ratones se las han comido». Finalmente, concluye que, dado que su cometido es el fomento del bien público, estima que es lógico que los caudales deban estar a su cargo. Por lo que respecta al comercio, en la misma fecha que el ayuntamiento, señala que más allá de continuar con debates estériles, que solo retrasan la solución, lo que procede es aplicar los arbitrios a la finalidad para la que se establecieron, coincidiendo con el comandante de Marina en el sistema de recaudación e inversión.

El 3I de marzo se ordena que los documentos se entreguen al director general de la Armada, quien emite su parecer el 29 de mayo. Su asesor expone que hay un pecado original en todo lo relativo a los arbitrios, como ya vimos, $y$ es el no tener presente nunca si pueden soportar un nuevo gravamen y si su producto alcanzará para el fin que se persigue, lo que al no producirse suscita quejas sobre su insuficiencia, su mala administración, y el deseo de intentar que la intervención, el control, sea la menor posible. El resultado es siempre el contrario al pretendido, pues los contribuyentes, sabedores de esta mala praxis, buscan cómo eludir el pago y al final los ingresos se reducen. Este sistema es el que explica que, a pesar de poseer arbitrios, todos «destinados a la limpia y conservación de la dársena y puerto, el puerto está a pique de perderse». El ayuntamiento falta a la verdad en lo que afirma sobre el médico, pues siempre se habló de abonarle su sueldo con los propios, jamás con los arbitrios. Esta irregularidad lleva 18 años reproduciéndose, «y nadie se lo ha contradicho hasta hoy. Vuestra excelencia [dirá] si esto es estar o no abandonado el manejo de los caudales públicos». El dictamen es severo: «no solo es injusto que el ayuntamiento haya identificado estos dos fondos [propios y arbitrios], pagando con el de arbitrios el 
gasto del médico, que corresponde al de propios, sino que es escandaloso que se excuse de contribuir a la limpia de la dársena a pretexto del gasto del médico». De los 7000 reales que producía el arbitrio de avería — que estaba arrendadoel médico recibía 5500, por lo que en el mejor de los casos el puerto recibiría 1500 reales al año, pues aún se disputaba si este resto debía tener este fin. Hay que «corregir y castigar lo pasado, y prevenir que el desorden se repita en lo venidero» ${ }^{82}$. Así, el ayuntamiento debe reintegrar, desde la creación de los arbitrios, la cantidad total que no haya destinado a la limpieza del puerto y no pueda demostrar que tenía autorización para emplear en otro objeto. Y deja de encargarse de la recaudación y administración de los fondos, para lo que debe formarse una junta integrada por dos miembros del comercio, dos regidores y el comandante de Marina, como presidente. El director general de la Armada, para no dejar cabos sueltos, incluso detalla el método que debe seguirse para el nombramiento de los representantes y su funcionamiento. Un comerciante estará encargado de la recaudación y el otro de llevar la cuenta y razón. Las obras deben contar con un presupuesto previo. La Junta se reunirá el primer día de cada mes, cuando se presentarán las cuentas. Estas se deben remitir a la Junta del Departamento en Ferrol el $3 \mathrm{I}$ de diciembre de cada año. El retraso de su presentación desde el 7 de enero llevaría aparejada una multa de 1000 reales a los dos vocales del comercio, que el ayuntamiento podría destinar a sus propios. Los caudales se guardarán en una caja en casa del presidente con tres llaves, custodiadas respectivamente por él, un diputado del comercio y un regidor. Los regidores tienen un papel relevante, pues su firma es obligada para poder abonar cualquier gasto. Se explicita de manera breve cuáles son sus funciones: «Las funciones de la Junta serán cuidar de la conservación de la dársena, administrar y recaudar los fondos asignados, que no podrán tener ninguna otra aplicación, bajo responsabilidad pecuniaria de aquella de todas las sumas que se distraigan a otro objeto» ${ }^{83}$.

En base al dictamen del director general de la Armada y del fiscal militar del Consejo del Almirantazgo se aprueba una real instrucción el 26 de octubre de 1815 que prescribe la instalación en Gijón de una Junta de puerto. La instrucción consta de 27 puntos, siendo el primero: «El ayuntamiento cesará desde el día en la administración y recaudación del arbitrio de muelle y para entender en ella se formará una junta con el título de conservación del puerto». El ayuntamiento protestará contra esta decisión, como era de esperar.

82 José Benítez, fiscal del Consejo de Guerra, a Félix Ignacio de Tejada, director general de la Armada. Madrid, 12 de mayo de 1815 . Conocía muy bien el expediente, pues el II de diciembre de 1814 se le remitió toda la documentación que había en Madrid.

${ }^{83} \mathrm{El}$ director general de la Armada. Madrid, 26 de agosto de 18I5. El Supremo Consejo del Almirantazgo manifiesta que está de acuerdo con todo. 


\section{LAS DESVENTURAS DEL PUERTO DE GIJÓN}

La real instrucción de 26 de octubre de 1815 detallaba cómo se efectuaba la elección de sus miembros, cuáles eran sus competencias y cómo se llevaban a cabo las deliberaciones. Sin embargo, no todo quedaba previsto reglamentariamente, y, por ejemplo, cuando en Gijón se plantee el nombramiento de un cobrador de arbitrios y de un secretario para la Junta, desde la corte lo que se hará es consultar a otros puertos qué se hacía en ellos para seguir su ejemplo. Pero tampoco esto servía. Pensemos que en el puerto de Tarragona el cobrador recibía el $2 \%$ de lo que recaudaba y el escribano 1500 reales catalanes, un reducido estipendio que este último compensaba por la circunstancia de que todas las escrituras de compras y ventas del puerto pasaban por él, mientras que en Gijón se solicitan para el primero el I0\% y para el segundo I I 00 reales. A primera vista podría parecer una arbitrariedad lo sugerido para el cobrador, pero se explicaba porque el caudal que se movía en el puerto cantábrico era muy inferior al del Mediterráneo -el salario real sería de 1000 reales-, se reducía al arbitrio de muelle y por menos importe nadie aceptaría ese empleo.

El ayuntamiento de Gijón se dirigió al Consejo Real, órgano competente en el gobierno de los fondos de propios y arbitrios municipales, quejándose de los dos instrumentos legales que daban forma a la Junta, la citada real orden y la instrucción de 20 de octubre de 1815 sobre la recaudación y aplicación de arbitrios destinados a la conservación y limpia del muelle y dársena de Gijón. Su maniobra se coronó con el éxito. Hacienda, en consideración a la real cédula de 26 de enero de 1786 y a una resolución de 9 de febrero de 1816 que la confirmaba, «ha propuesto a su majestad la revocación de las providencias dictadas en este asunto por el Ministerio de Marina» ${ }^{84}$. Pero antes de publicar esta resolución se consulta al secretario de Marina si tiene algo que exponer y él da traslado al Supremo Consejo del Almirantazgo, cuyo fiscal redacta un informe. Como el asunto no era nuevo, se toma como referencia una consulta de 26 de agosto de 1815 , que se halló en la base de la instrucción de octubre de ese año.

En 1815 la corte aprobó que la recaudación y aplicación de los arbitrios destinados al puerto debían correr a cargo de una junta integrada por dos regidores municipales, dos representantes del comercio y el comandante de Marina ${ }^{85}$, resolución que tuvo presente la real cédula de 26 de enero de 1786, «en que terminantemente se encarga a los ayuntamientos y junta de propios de los arbitrios de esta naturaleza». El fiscal rechaza de plano que se revoquen por Hacienda

${ }^{84}$ El secretario de Hacienda, Martín de Garay Perales, al secretario de Marina, José Vázquez Figueroa. Madrid, II de junio de 1817 .

${ }^{85}$ Así será hasta que por una Real Orden de 28 de julio de 1825 pasen a encargarse los empleados de la Real Hacienda. 
las decisiones de Marina, pues el ayuntamiento solo cita una parte de la cédula de 1786 y obvia otra que es clave:

Que las justicias y juntas de propios de los pueblos deben continuar en llevar la cuenta y razón de los caudales destinados a las obras de puertos que se costeen con arbitrios o propios de los mismos pueblos.

Que el facultativo puesto por la Marina que las dirija intervenga y vise las cuentas, remitiéndose copia de ellas a la Junta del Departamento respectivo.

Por tanto, las medidas aprobadas en 1817 no cuestionan ni vulneran la real cédula de 1786, sino que van en la misma línea, pues el ayuntamiento se haya presente en la Junta de obras y el oficial de Marina que las dirige ya tenía conferida capacidad de intervención desde 1786. Pero todavía hay muchos más argumentos que desmontan las pretensiones del ayuntamiento. Los arbitrios con los que financia sus actividades en el puerto la Junta proceden exclusivamente del derecho de avería, al que solo contribuyen los comerciantes marítimos, y del de barricaje, que afecta solo a los comerciantes. Por tanto, no se trata de propios y arbitrios municipales, sino solo de arbitrios, y dado que los afectados son comerciantes, la villa y la Marina, una Junta en la que están todos ellos representados es el mejor mecanismo para controlar su recaudación e inversión. El dictamen del fiscal, tras enumerar las argumentaciones técnicas legales, no evita señalar que detrás de esta insistencia del ayuntamiento existen intereses espurios, que nada tienen que ver con la mejora del puerto:

El fiscal militar cree de su deber llamar la atención de este supremo tribunal [del Almirantazgo] hacia el empeño con que el ayuntamiento de Gijón pretende tener un conocimiento y manejo exclusivos sobre los arbitrios de la cuestión; pues constando en el mismo expediente que mientras así ha sucedido el puerto de Gijón ha sido abandonado hasta llegar el caso de inutilizarse; y que el dicho ayuntamiento lejos de atender a su limpia y conservación ha aplicado los referidos arbitrios para el pago de sueldo al médico capitular y a otros objetos inconexos y muy distantes del principal; es presumible que en tal pretensión se proponga un fin siniestro, y no el buen servicio de su majestad y del Estado.

El ayuntamiento de Gijón, aprobada la creación de la Junta, va a adoptar una actitud obstruccionista, empleando toda suerte de maniobras dilatorias. Así, mientras los comerciantes casi de manera inmediata eligen a sus dos representantes en la Junta, el primero dice que no ha recibido la orden por el conducto correspondiente del Ministerio de Gracia y Justicia — se la había entregado el comandante de Marina- y más tarde que no procedía la elección mientras no resolviera el Consejo de Castilla una consulta que le había realizado sobre este particular. Los diputados del comercio (Toribio Acebal y José García Rivero) 


\section{LAS DESVENTURAS DEL PUERTO DE GIJÓN}

presentan una exposición al comandante donde plantean las consecuencias negativas de este impasse, pues nadie estaba cobrando los arbitrios, ni el ayuntamiento que no debe ni la junta que no puede. Para ellos todo se reduce a que los regidores no quieren dejar de percibir y gestionar los arbitrios. Le piden que considere ya constituida la junta y se inicien los trabajos o que envíe a la corte su texto, que será lo que hará el comandante. Este en el oficio que dirige al ministro de Marina deja patente los graves deterioros del puerto -el 2 de noviembre de I8I5 había remitido un plano donde los detallaba-, que exigían una reparación costosa. Califica la obstinación del ayuntamiento como «maliciosa», que provoca frustración entre los vecinos, que «creían que ya cesarían las inversiones oscuras de estos caudales», y dolor por el puerto, ya que «la corporación que más debía fomentarlo lo desatiende ${ }^{86}$.

El 30 de julio de 1816 se acuerda darle un plazo al ayuntamiento de dos días para que elija sus dos diputados en la Junta, pasado el cual, esta se considerará constituida y sobre aquel caerá la pena que se estime oportuna. Su respuesta se reduce a acordar convocar una reunión extraordinaria para tratar este asunto, por lo que el 7 de septiembre se constituye la Junta. Como era de esperar, el ayuntamiento no colabora con el comandante cuando le solicita la relación de personas que adeudan el arbitrio de muelle, que cobraba el ayuntamiento, y con displicencia señala uno tener noticia de las facultades y circunstancias con que se había instalado la que dice el referido ayuntamiento supuesta Junta». El ayuntamiento desea saber el número de comerciantes que participaron en la elección de sus dos diputados y bajo qué facultades se efectuó, y a qué personas se convocó para la llamada Junta, «porque hay muchos que ignoran semejante Junta», según el regidor Juan Eugenio García de Salas. El comandante identifica a Salas como el «promotor del intento que formó el ayuntamiento de obstruir las operaciones de la Junta, y que esto lo hace por razones que si fuese preciso lo dirá» ${ }^{87}$ y solicita una sanción económica. Por Real Orden de 24 de noviembre el ayuntamiento es multado por desobediencia con 500 ducados a beneficio de la Junta y se le conceden tres días para cumplir la orden de nombrar a sus dos representantes. Esta multa dio lugar a otros problemas, ya que el receptor de penas de cámara de la Audiencia aplicó el descuento de la quincena (366 reales y 22 maravedís) en concepto de depósito, lo cual era legal pero en este caso podía ha-

\footnotetext{
${ }^{86}$ Citado en un informe dirigido a la sala de gobierno. 22 de mayo de 1816.

${ }^{87}$ El comandante nunca aclarará estas palabras. Posiblemente se refiere a que tanto Salas como el otro diputado, Modesto Zarracina Llanos, eran las personas a las que quienes deseaban optar a la plaza de médico en Gijón, con un sueldo de 600 ducados, debían dirigir sus memoriales. Gaceta de Madrid, 1817, p. 1384; Gaceta de Madrid, I815, p. 500. Ya vimos de dónde había procedido durante casi dos décadas el dinero que recibía el médico en Gijón.
} 
berse entregado directamente y no hubo distribución ni custodia. Ahora que estaba neutralizado el ayuntamiento reaparecía la Audiencia. El comandante de Marina dirigió varios oficios a la Audiencia, inútilmente, de modo que el Supremo Consejo del Almirantazgo resolvió el 16 de mayo de 1817, sentando jurisprudencia, y se dio traslado a las autoridades navales en la Península y Ultramar ${ }^{88}$. Ahora sí obedece el ayuntamiento, pero sus representantes lo que promueven es inhabilitar la Junta, solicitando que se anule la elección de los dos vocales del comercio, «por no ser hecha conforme a las leyes». 1817 comienza con esta disputa, en la que el comandante defiende la elección y el Consejo acuerda estudiar las solicitudes de ambas partes, pero dejando claro que la Junta debe continuar sus trabajos - «no interrumpa sus sesiones y tareas por ningún motivo ni pretexto ${ }^{89}-$ y que ninguna de sus decisiones podrá ser anulada aunque se demuestre irregularidad en su composición, ni se pueden cuestionar las anteriores actas, pues el ayuntamiento no envió representantes por libre iniciativa e incumpliendo órdenes reales. Se evitaba así que las obras se retrasasen y cualquier efecto retroactivo. La Secretaría de Marina pone todo de su parte para que la Junta desarrolle sus tareas de modo efectivo ${ }^{90}$. Ahora bien, sin éxito. La Junta es un campo de batalla. La documentación ofrece los argumentos de cada uno de los bandos y es una prueba de las inexactitudes y parcialidad de las exposiciones. Es de imaginar la tensión en la Junta, pues la primera actuación del representante del ayuntamiento - el otro se encontraba en la corte para emprender acciones contra la Junta, para lo cual le entregaron poderes- será dar cuenta de la representación del ayuntamiento en la que se declaraba ilegales a los otros dos diputados y todas las actas en las que hubieran participado. El ayuntamiento no había cedido lo más mínimo, simplemente deseaba evitar otra sanción y había considerado que se imponía trabajar desde el seno de la Junta para bloquear cualquier decisión.

No deja de ser curioso que sea el ayuntamiento de Gijón, entre todas las villas portuarias de España donde existe la misma Junta y práctica, el único que exige controlar estos arbitrios y que considere que se atenta contra sus facultades. Para el fiscal, el ayuntamiento de Gijón no le ofrece la menor de las garantías y aceptar su petición sería equivalente a «irrogar perjuicio al comercio de aquella ciudad, privándole del derecho de saber si se invierten los tales arbitrios en su

88 «En las condenaciones pecuniarias impuestas a favor de la cámara o real fisco de Marina, se cuide escrupulosamente de su pronta e inmediata entrega del importe íntegro a las autoridades». Acuse de recibo de Torcuato Piedrola, comandante de Marina, al secretario del Supremo Consejo del Almirantazgo. Cartagena de Indias, 19 de noviembre de 1817 .

${ }^{89}$ Oficio al Consejo. Madrid, 14 de enero de 1817.

90 El secretario de Marina solicita un informe que contribuya a «que el servicio se haga bien y se corten de una vez las rencillas». Vázquez Figueroa a Diego de Mesa, fiscal del Consejo del Almirantazgo. Palacio, 10 de enero de 1817. 


\section{LAS DESVENTURAS DEL PUERTO DE GIJÓN}

único y principal objeto». Por otro lado, inhibir al comandante de Marina de conocer en esta materia le impediría llevar a cabo su labor, al no disponer de información para realizar los presupuestos y programar las obras. Se impone implementar las medidas aprobadas en 1815 - constitución de la Junta con todas sus facultades- y poner fin a la interpretación «violenta» durante décadas por el ayuntamiento de la real cédula de 1786 , que además siempre fue en detrimento del puerto". Y así se aprueba y publica el 16 de octubre de 1817. La victoria inicial en Hacienda del ayuntamiento, que había aceptado derogar la real instrucción de 26 de octubre de 1815 - su recurso, de modo inteligente, silenciaba información-, se revierte y anula. La Secretaría de Marina no va a dejar pasar la ocasión de exponer que la propia creación de la Junta es un mecanismo para acabar con la ocultación, apropiación y malversación que el ayuntamiento ha realizado de los arbitrios desde un principio. Las máximas que subyacen en la Junta son que quienes contribuyen a sus fondos sean quienes los controlen y que se destinen a los fines para los que se recaudan. Esto para Gijón era algo novedoso y todas las resistencias procedían de que la mera existencia de la Junta significaba el punto y final a prácticas reprobables y la amenaza de hacerlas explícitas documentalmente y exigir el resarcimiento de las cantidades malversadas.

Lo acontecido en el ayuntamiento de Gijón se debió a la inexistencia de control de sus actuaciones y a una interpretación torticera de la legislación. El ayuntamiento siempre alude a la Real Cédula de 26 de enero de 1786 -que también interpretaba de modo parcial-, cuando lo que afectaba al puerto era la cédula de 27 de enero de 1774 que se refería a arbitrios concedidos para fines determinados, tras ser informados por el comercio y aprobados por el ayuntamiento, que estaba encargado de su recaudo, administración e inversión en el objeto prestablecido. Había fracasado la intervención, que debían desempeñar dos diputados del comercio, y el especial encargo al oidor decano de la Audiencia de vigilar la aplicación de los fondos. Por si no estuviera suficientemente claro, por reales órdenes de 31 de marzo y 23 de mayo de 1804 los derechos de avería y barricaje se pusieron al cuidado de dos personas del comercio, bajo la inspección del comandante de Marina. El ayuntamiento de manera sistemática vinculó todos los arbitrios y dispuso de ellos sin ofrecer jamás cuentas ni de su montante ni de su destino. El resultado fue el abandono del puerto, que debió ser el destinatario de todos esos caudales. Todas «las malversaciones o extravíos» fueron perpetrados por el ayuntamiento, pero porque el oidor nunca ejerció su labor de vigilancia y denuncia de las irregularidades. El interés del ayuntamiento no es otro que persistir «en sus ilegítimas miras de extraviar tales productos a objetos

91 El informe del fiscal se halla en la resolución del Supremo Consejo del Almirantazgo en Sala de Gobierno. Madrid, 26 de agosto de 1817. 
«extraños a los de su establecimiento» ${ }^{92}$. Demuestra desentenderse de la propia villa, pues del puerto dependen el comercio y la economía de muchos vecinos $y$, por extensión, de la localidad. La mejor prueba de lo conveniente de la existencia de la Junta y de sus beneficios para el puerto es que, tras años de abandono, el puerto comienza a mejorar.

Por lo que respecta al ayuntamiento se empleará a fondo en dificultar, paralizar, obstaculizar, complicar, etc., los trabajos de la Junta. Empezando porque se niega a devolver lo empleado de manera irregular en el

tiempo que han administrado los arbitrios de aquellas obras y limpias en razón a que estos han estado siempre englobados con todos los demás de la villa, y que en los años de la guerra se ha usado indistintamente de todos para cubrir los gastos que ha originado ${ }^{93}$.

Persigue encubrir como negligencia y caos contable su malversación. No se dirime este enfrentamiento por controlar los recursos de la Junta, pues en 1817 su presupuesto era de 30000 reales, cifra que nada tiene que ver con las que se invirtieron en la segunda mitad del XVIII, sino que se enmarca en una larga tradición de conflictos jurisdiccionales, de tensiones sociales en el seno de una pequeña población costera, donde los intereses de la minoría de comerciantes no encuentran respaldo político en el ayuntamiento y en la fractura que está sufriendo el Antiguo Régimen tras ver golpeado sus muelles por el temporal ilustrado, revolucionario y bélico desde 1793 a $1815^{94}$.

\section{CONCLUSIÓN}

De manera incuestionable, los problemas a los que se enfrentó el puerto de Gijón tuvieron origen exclusivo en los efectos de la naturaleza. Sin embargo, la dilación en el tiempo de su resolución, la imposibilidad de aplicar un proyecto ambicioso, o al menos estable y no sujeto a variaciones permanentes, la escasa relación entre la inversión efectuada y la mejora real de la infraestructura, los obstáculos que erigen las más variadas instancias administrativas, en suma, cuanto hemos presentado en las páginas precedentes, evidencian que sus muelles debieron protegerse de las asechanzas de los hombres igual o más que de la hostilidad del océano. Menos a su finalidad específica, los arbitrios concedidos para la reparación y mantenimiento del puerto de Gijón se destinaron a cualquier objeto: el

92 En el oficio de Vázquez Figueroa al secretario del Almirantazgo. Palacio, I5 de octubre de 1817.

93 En un informe fechado el 13 de abril de 1818.

94 Pese a lo reducido del presupuesto, el comandante considera que con otra cifra similar el muelle «quedará con toda solidez por una larga serie de años». Informe al Supremo Consejo del Almirantazgo. Madrid, 30 de abril de 1817 . 


\section{LAS DESVENTURAS DEL PUERTO DE GIJÓN}

hospicio y la escuela de dibujo de Oviedo, el médico de Gijón o una batería en el ayuntamiento de Navia. Sin embargo, el resto de poblaciones costeras asturianas consideran que Gijón es el puerto privilegiado, protegido, al que se destinan los recursos que se detraen de otros puertos (lo cual es cierto ${ }^{95}$ ), el elegido para contar con una magnífica estructura portuaria. Es innegable que fue el seleccionado, pero no solo en el sentido positivo que creían sus émulos. Los ingenieros que reconocen Gijón en el siglo XVIII señalan que la naturaleza no fue muy generosa con la villa, lo que implicó un hándicap inicial para su puerto. Sin embargo, fueron mayores y sorprendentes las trabas que le crearon tanto las instituciones locales - ayuntamiento de Gijón - como provinciales -Audiencia e Iglesia de Oviedo-, pero que, como hemos visto, aunque con grave coste para su conservación, irá superando paulatinamente. Esto también explica que en 1827, como si para el puerto fuera a resultar sorprendente, el intendente de Asturias, como el ayuntamiento de Gijón medio siglo antes, realice una interpretación inicua de la real cédula de 27 de enero de 1774 sobre los arbitrios destinados a las obras y la Junta del puerto deba salir, tampoco es nuevo, a defender unos muelles que desde 1742 debían temer a los hombres, sus instituciones e intereses más que a la furia del Cantábrico ${ }^{96}$. La Junta volvió a vencer, porque, como siempre, va a tener en la Secretaría de Marina (o en la legalidad) su mayor defensor. La Junta será el instrumento en el cual se puedan conciliar objetivos distintos, cuando no enfrentados, para que confluyeran en beneficio exclusivo del puerto, o que en el peor de los casos al menos dirimieran sus disputas en Gijón y dejaran de inundar con sus recelos y discordias la Secretaría de Marina:

La Marina quiere aquí tener a su disposición el fondo del derecho o arbitrio de muelle. El ayuntamiento no quiere soltarlo, porque dice que hay otro fondo para este objeto. Ese otro fondo es el derecho de avería que se recauda en la aduana y se entrega a un diputado del comercio, que a la sombra de su consulado y de la Marina quiere también manejar ese fondo, $y$ entre tanto ninguno de los tres nos dice qué se ha hecho de lo colectado hasta aquí. Todo está destinado a la dársena, y la dársena está a pique de perderse y cegarse el puerto, porque no se ha hecho en ella obra alguna hace muchos años ${ }^{97}$.

\section{BiBLIOGRAFÍA}

Adaro Ruiz-Falcó, Luis, El puerto de Gijón y otros puertos asturianos, Gijón, Cámara Oficial de Comercio, Industria y Navegación, 1976-1986, 4 tomos.

95 García Hurtado, 2020b.

${ }^{96}$ Luis María de Salazar, secretario de Marina, a Juan María Villavicencio, director general de la Armada. Palacio, 6 de abril y 20 de mayo de 1827. El director general de la Armada a Salazar. Madrid, 9 de mayo de 1827.

97 José Benítez al director general de la Armada, Tejada. Madrid, 3। de diciembre de $|8| 4$.

MEMORIA Y CIVILIZACIÓN 24 (202I): 423-463 [I-4I] 


\section{MANUEL-REYES GARCÍA HURTADO}

Alvargonzález Rodríguez, Ramón María, «Jovellanos y las obras públicas», en Jovellanos. El hombre que soñó España, Madrid, Encuentro, 2012, pp. 209-2I8.

Coronas González, Santos Manuel, «Un magistrado navarro-aragonés: don Isidoro Gil de Jaz, regente de la Audiencia de Asturias (1749-I754)», en Un jurista aragonés y su tiempo. El doctor Juan Luis López, primer marqués del Risco ( $1644-$ I 703), ed. Miguel Ángel González de San Segundo, Zaragoza, Diputación General de Aragón, 2007, pp. 189-238.

Franch Benavent, Ricardo, «El crecimiento del tráfico comercial y la mejora de la infraestructura portuaria en el Mediterráneo español durante el siglo XVIII», en Las innovaciones de la Armada en la España del siglo de Jorge Juan, ed. Manuel-Reyes García Hurtado, Madrid, CSIC, 2020, pp. 25-62.

García Hurtado, Manuel-Reyes, «El mantenimiento de las estructuras portuarias en el siglo XVIII: Un modelo de análisis», en Fronteras de agua. Las ciudades portuarias y su universo cultural (siglos XIV-XXI), ed. ManuelReyes García Hurtado y Ofelia Rey Castelao, Santiago de Compostela, Universidade de Santiago de Compostela - Universidade da Coruña, 2016, pp. 359-391.

García Hurtado, Manuel-Reyes, «Piedra sobre roca. Las poblaciones portuarias asturianas en el siglo XVIII entre proyectos y el Atlántico», en Soltando amarras. La costa noratlántica ibérica en la Edad Moderna, ed. Manuel-Reyes García Hurtado, A Coruña, Universidade da Coruña, 2019, pp. I87-25I.

García Hurtado, Manuel-Reyes, «Dominar la naturaleza. Construir, limpiar y acondicionar puertos en el siglo XVIII en España: Pasajes y La Mora», Tiempos Modernos, I0, 4I, 2020a, pp. I77-205.

García Hurtado, Manuel-Reyes, «Los puertos asturianos en el siglo llustrado: el combate contra una debilidad crónica», Revista de História da Sociedade e da Cultura, 20, 2020b, pp. 79-102.

García Leduc, José Manuel, Apuntes para una Historia Breve de Puerto Rico (Desde la prehistoria hasta 1898), San Juan, Isla Negra Editores, 2007.

González de San Segundo, Miguel Ángel, «Los ministros de la audiencia de Asturias en el reinado de Felipe V (notas para su estudio)», en Historia iuris. Estudios dedicados al profesor Santos M. Coronas González, Oviedo, Universidad de Oviedo - KRK, 2014, I, pp. 755-783.

Hinarejos Martín, Nuria, «El ingeniero Tomás O’Daly en Puerto Rico», en América: cultura visual y relaciones artísticas, ed. Rafael López Guzmán, Yolanda Guasch Marí y Guadalupe Romero Sánchez, Granada, Universidad de Granada, 2015, pp. 43-50.

Jovellanos, Gaspar Melchor de, «Exposición al ministro de Indias sobre establecimiento de un consulado en Gijón», en Obras publicadas e inéditas de Don Gaspar Melchor de Jovellanos. Colección hecha e ilustrada por Don Cándido Nocedal. Tomo segundo, Madrid, M. Rivadeneyra, I859, pp. 5I2-5I6.

Jovellanos, Gaspar Melchor de, Plan general de mejoras, propuesto al Ayuntamiento de Gijón por el Excmo. Sr. D. Gaspar Melchor de Jovellanos, Gijón, Imp. y lit. de Torre y Comp., I89I.

Juanto Jiménez, Consuelo, «Notas para el estudio de Isidoro Gil de Jaz y la Real Audiencia de Asturias (I749. 1752)», Boletín de Letras del Real Instituto de Estudios Asturianos, 66, 179-180, 2012, pp. II7-128.

Junceda Avello, Enrique, Historia del Real Hospicio y Hospital Real de la ciudad de Oviedo, Oviedo, Instituto de Estudios Asturianos, 1984.

Mallada Álvarez, Nicanor Enrique, «Los niños abandonados asturianos en el contexto de la llustración», en Comercio y cultura en la Edad Moderna. Actas de la XIII Reunión Científica de la Fundación Española de Historia Moderna, ed. Juan José Iglesias Rodríguez, Rafael M. Pérez García y Manuel F. Fernández Chaves, Sevilla, Universidad de Sevilla, 20I5, 2, pp. 208I-2I00.

Maruri Orrantia, David, «La nobleza de Navarra (s. XVI-XVII-XVIII). Índice de la obra de D. Isidoro Gil de Jaz», Zangotzarra, 5, 200I, pp. 8I-I52.

Menéndez González, Alfonso, «Los regentes de la Audiencia de Asturias en el siglo XVIII», Boletín del Instituto de Estudios Asturianos, 133, 1990, pp. 27-44

Menéndez González, Alfonso, La Real Audiencia de Asturias, I7/8-1854, Oviedo, KRK, 20 II.

Ordenanza de S. M. para el régimen y gobierno militar de las matrículas de mar, Madrid, Imprenta Real, 1802.

Pérez de Castro Pérez, Ramona, Los regidores del concejo de Gijón durante la Edad Moderna (siglos XVII-XIX), Oviedo, Real Instituto de Estudios Asturianos, 1998.

Pérez Fernández-Turégano, Carlos, «El Almirantazgo del Infante don Felipe (I737-I748). Conflictos competenciales con la Secretaría de Estado y del Despacho de Marina», Anuario de Historia del Derecho Español, 74, 2004, pp. 409-473.

Peribáñez Caveda, Daniel, «La libertad de comercio con América y el establecimiento de las bases del tráfico ultramarino en el puerto de Gijón durante el reinado de Carlos III», Moneda y Crédito, 186, 1988, PP. 4I-56. 


\section{LAS DESVENTURAS DEL PUERTO DE GIJÓN}

Peribáñez Caveda, Daniel, Comunicaciones y comercio marítimo en la Asturias preindustrial (I750-/850), Gijón, Puerto de Gijón, 1992.

Pozas Pozas, María Jesús, «El puerto de Santander y el comercio marítimo en el siglo XVIII», en Comercio y cultura en la Edad Moderna. Actas de la XIII Reunión Científica de la Fundación Española de Historia Moderna, ed. Juan José Iglesias Rodríguez, Rafael M. Pérez García y Manuel F. Fernández Chaves, Sevilla, Universidad de Sevilla, 20I5, 2, pp. 553-567.

Rodríguez-Villasante Prieto, Juan Antonio y José Troya Calatayud, Historia del puerto de Gijón, Madrid, Ministerio de Fomento, 2002.

Teijeiro de la Rosa, Juan Miguel, «El comisariado en el ejército y la marina del siglo XVIII», en Soldados de la Ilustración. El ejército español en el siglo XVIII, ed. Manuel-Reyes García Hurtado, A Coruña, Universidade da Coruña, 2012, Pp. 263-290.

Vázquez Cienfuegos, Sigfrido, «El Almirantazgo español de I807: la última reforma de Manuel Godoy», Hispania. Revista Española de Historia, 72, 24I, 2012, pp. 475-500. 